\title{
Chapter 5 \\ Reality Bites: Listening to Children, Parents, Teachers and Other Experts
}

\begin{abstract}
This is one of the central parts of this book. It elaborates the emergence of different categories related to the groups of participants of the study (children with disabilities, parents, teachers) as well as it includes the additional perspective of experts. This means that four perspectives on the situation of children with disabilities in schools in Addis Ababa are presented. By referring to the categories that developed from analysing the interviews of children, parents, teachers and other experts, the mentioned perspectives are discussed. Having elaborated the categories for each perspective, each part is concluded with a summary that focuses on the meaning of education for each of the participating groups. This is then linked to a discussion in relation to educational equity.
\end{abstract}

At the beginning, the big question was how to find participants in Addis Ababa who would be willing to tell me their stories, which - very often - started with painful memories of the moment when parents learnt that their child had a disability. These times were coined by uncertainties, grief, guilt and not knowing how to cope with the situation in a life which was already difficult because of poverty. Talking to the children, I just asked them about their daily life in school and at home and about their experiences and impressions. In most cases, they were very excited to tell me about their thoughts, dreams and desires. Lastly, the teachers were sometimes suspicious because they did not know where all the questions would lead to. In the end, finding participants was not a problem. All of the participants were very happy about the fact that someone had come to listen to them.

Looking at the research situation, we have to see that the child with a disability is identified as such by persons that surround him/her. People who have a relation with the child, people who talk about the child, people who construct environments around the child and consequently the child him/herself define what is special about him/her and why. 
I chose to speak to children, parents, teachers and other experts as sources of information because I thought that those people would be able to give information about the situation of children with disabilities at school. Additionally, observations in the classes and in the school compounds provided me with information that the interviewees might not have been able to give. All these perspectives opened a compact set of views on a certain aspect. That means that the child with a disability was constructed within these views and additionally through my interpretation of these views.

Throughout the process of analysing the data, it became clear to me that emerging topics have to be analysed based on the different perspectives, meaning from the parents', teachers' and children's points of view, rather than looking at each "case" (child-parent-teacher), as categories developed (and were constructed) in relation to one or the other group.

I considered it as essential to analyse how the disability of the child affected each of the participants and vice versa. By analysing emotions, issues that were raised, actions and reactions in the data, it was possible to get an impression of what disability meant to the people and hence of how the parents, teachers, experts and children constructed and maybe also deconstructed disability in relation to the field of education. I followed Charmaz' way of analysing the data: "I pieced together what people said and did and looked for their implied meanings. In this way, a constructivist goes beneath the surface and enters the liminal world of meaning" (Charmaz 2009, 144).

The goal of this approach to analysis was to obtain an answer to the question of which environmental factors were identified by the participants as influencing education for children with disabilities. In this regard, the participants exhibited different roles: children on a "trying to find my place" level, parents on a "caring about the child" level, teachers on a "being responsible for education" level and experts on a "having to know what the problem is" level.

In this part, I will explain how I moved towards the final core category of feeling like a family. I attempt to do this by using the different perspectives of the interviewed children, parents and teachers as well as experts. My specific aim was to discover the "implicit meanings" (Charmaz 2003, 314) of the participants' experiences. The analysis of the interviews led towards the development of categories $^{1}$ that reflect the participants' actions. I will guide you to the main topics which emerged from my interviews and became categories. As a support, I will use some network views to better visualise the connections between these topics (categories).

However, it was not considered as productive to strain your attention by adding too many detailed network views. Instead, detailed reflection of the analytic process and condensed versions of network views will clarify the construction of categories.

\footnotetext{
${ }^{1}$ In the following chapters, titles of categories are written in italics.
} 
In the research at hand, the focus was placed on spelling out the characteristics of each category to enable you to grasp the meaning of the categories. Therefore, at the end of each chapter on a category, you will find the condensed network views of the most significant properties (in bold in the text) and further influences of that category. ${ }^{2}$

Diagrams can enable you to see the relative power, scope, and direction of the categories in your analysis as well as the connections among them. You may find that diagrams can serve useful and diverse purposes at all stages of analysis. You might revise an early quick clustering about a category into a more exacting form as a diagram illustrating the properties of a category. You might develop a conceptual map that locates your concepts and directs movement between them. (Charmaz 2006, 118)

For these reasons, throughout the following part of the book, diagrams are used to support the analysis as well as to make the process of the analysis transparent.

\section{Listening to the Children}

When asking children what was necessary to become what they were dreaming of, many of them mentioned having to be a good student (an important detail at this point may be the fact that all the interviews were conducted at school). This credo was repeated by parents and teachers alike. The children were convinced that by studying hard they could reach what they aspired in their future. One of these aspirations was to support and help their families and overcome poverty:

$\mathrm{Y}^{3}$ : What do you want to be in the future? What is your ambition?

E: I want to support my mother and father. I want to provide them with everything they need. That's all. (Embaye, child)

Their other aspiration was to become a full member of society, to be successful and to make a meaningful contribution to the community: "In order to lead a good social life with the community, I want to help people like me. Besides, I want to help my mother and father" (Embaye, child).

\footnotetext{
2 "Properties of categories and subcategories should be considered in terms of their dimensions or the range of variance that the property demonstrates" (Birks and Mills 2011, 98). The authors furthermore give an example of this analytic process: the category "walking the dog" can have properties like time, enjoyment and energy. These properties again can have dimensions like "spending a short amount of time" because it is raining (Birks and Mills 2011, 98). In this work, dimensions of properties are not elaborated specifically, as not all of the properties have dimensions. It was regarded as more useful to deeply analyse and describe the properties themselves not referring to dimensions in particular. However, in some cases, dimensions of categories were listed (e.g. for the category parental support), and consequences were added to the network views if considered important.
}

${ }^{3} \mathrm{Y}$ stands for Yeshitla Mulat, the interpreter. 
The categories developing a positive self-concept and question of belonging emerged from the children's interviews. To add a more exact description of the categories, keywords (e.g. necessary basis) to characterise the categories in the process of children receiving education are attached to each category (this is done also for the categories which emerged from the other interviews).

\section{Developing a Positive Self-Concept: Necessary Basis (For Development/Change)}

School attendance meant an increase in the positive perception of self for the children that I interviewed.

New possibilities seem to open for them and lead to new perspectives in their lives. A major part of this category is the influence of family, friends and surrounding regarding support. Children who are supported to reach their goals are also more included in the community than children who are not supported. Furthermore, the goals of supporting the family and becoming a valued member in society become more achievable through education, as children get the feeling of being able to reach those goals.

Y: What are those things that entertain you?

E: $\quad$ For me, the best sport is education. (Embaye, child)

The development of a positive self-concept of the children as related to getting access to school became clear to me only during the second phase of the field research. The children told me that attending a school gave them the possibility of becoming full members of the community as well as of their families. Consequently, their self-esteem and self-perception were positively influenced by receiving education.

One important element of this development is the ability to support and help the family. Even though the category itself developed only later, the aspect of help and children wanting to help and be able to help appeared already in the very early stages of the analysis. The children reported that they needed education to be able to help their parents as well as people in need, especially people with disabilities. There was a high awareness of general problems for disadvantaged people, like homeless or ill people, living in Addis Ababa.

E: I think about the society. There are many beggars. I want this problem to be eliminated.

Y: $\quad$ Do you sympathize with them?

E: I wish something to happen. If I get a house, I will bring them together. I will treat those who are sick. I would do this if there are people who assist me. (Embaye, child)

Embaye here speaks about his wish to help but also mentions that he would need support for this. Being able to help can be identified as a property of devel- 
oping a positive self-concept. It is related to the children being given meaningful tasks or the feeling that they are needed. Above all, the children felt that they were needed if they could act as supporters of their family. Thus, having tasks at home gave them a feeling of being needed and valued. "On Saturday, I usually wash my school uniform and let it dry. After that I clean everything, and then I clean my house. If my Mom is at home, I will arrange everything so that she can make coffee" " (Yirgashew, child). In this quotation, Yirgashew fulfilled tasks that supported his mother, which gave him a function in the family and raised his self-esteem.

As mentioned above, the aspect of studying hard was strongly emphasised during the interviews. Studying hard is related to the children's striving to be successful in their education. Their positive self-concept is supported because the children can actively contribute to reaching their goals. Furthermore, the positive effects are enhanced if predefined goals are achieved. In this context, possibilities to study hard depending on their own capacities, ${ }^{5}$ time and space at home as well as support from their home or friends have to receive attention. Sometimes the children spoke about not having a desk or room to study at home. This aspect is closely related to the parents' category parental support and the aspect of support in general. In other words, support in this context may be a key element contributing to the development of a positive self-concept by enabling the children to study hard and consequently opening up further possibilities. One of these possibilities can be that of being able to help people in need after having finished education and working in an appropriate profession. This adds to their feeling of being able to become a valued member of society, which is clearly linked to aspects of the capability approach (reaching valuable beings). Therefore, the possibility to contribute to and be part of social life already leads to a positive self-image.

Becoming a valued member of society is related to knowing what is valued in society. Health was repeatedly mentioned by the parents as an important value. They considered disability as something that is not healthy, even though they did not put it on the same level as illness. Having a disability was seen as the opposite of being normal. This is why, very often, being healthy was considered to be one of the conditions for being able to support the family and contribute to the community. Looking at it from this perspective, disability automatically excludes children from participating in family and community life as a full member. Therefore, it is even more important for children to be able to counteract stigma and exclusion

\footnotetext{
${ }^{4}$ Making coffee is a traditional event in Ethiopian culture.

${ }^{5}$ A question that might arise here is to what extent children with "intellectual disabilities" can study hard. Studying hard is not necessarily only related to academic subjects but also includes things that are of importance to the children. For instance, the children were proud to be able to sing a song for us or demonstrate other achievements like counting or writing their names. All these things can also be studied at home.
} 
by being educated "like normal children". Through education disability seems to lose some of the negative connotations, as children with disabilities are not expected to be able to learn. Proving the opposite by receiving education provides an argument against such prejudices and supports the development of a positive self-perception. This leads to statements like, "we are able to act like other children if given the possibilities".

In some cases, the children were able to speak out for themselves and to bring about change at school. Such an experience counteracts a feeling of helplessness and promotes the feeling of being able to change conditions and circumstances. "One teacher got transferred; he didn't know sign language. He taught us only by speaking. We complained about his way of teaching; as a result they changed him" (Berhanu, child). Here, the children experienced that their opinion was valued. This is a very important step towards strengthening their self-esteem.

Consciousness of support is another important factor that sustains the development of a positive self-concept. Many of the children knew that they were supported by either their parents or their teachers or both.

Y: $\quad$ The last card is about family. Tell me about your family.

Yo: If you have a family, you will get support. (Yirgashew, child)

This quotation indicates a strong conviction of and trust in the system of "family". Additionally, friends ${ }^{6}$ played an important role in regard to having people who help and support them in reaching their goals. These goals were often related to supporting the family or aspiring professions like teacher or doctor that serve people and the community. Besides, groups of people who were there to support the child to be able to succeed indicate the children's degree of involvement and acceptance at school, in the community, etc. In other words, they were visible, and their needs were noticed and respected by the environment. ${ }^{7}$

Furthermore, the expectations which parents and teachers had of the child played a significant role. "Our parents expect us to learn like other children, be successful and help them" (Embel, child). It seems interesting to look at the expression "like other children" in this quotation: education seems to make the children more "normal". The children strived to satisfy their parent's expectations and felt valued by being expected to achieve certain things, as this indicates that they are thought to be able to accomplish specific tasks. This is why receiving education gave the children the possibilities to fulfil the expectations of their parents and teachers. It became clear that expectations were communicated to children directly or indirectly. Moreover, as soon as children with disabilities attended a school, the expectations of them changed and grew in some cases. "[...] [my parents] want me to become a medical doctor" (Serawit, child). This indicates that the parents had higher expecta-

\footnotetext{
${ }^{6}$ Having friends is an interesting topic within the field of research; however, no category developed in relation to it. Therefore, friends are not a major aspect in the book at hand. However, it might be worth exploring the friendship aspect in another paper.

${ }^{7}$ Not to be understood in terms of a pity-based charity model of disability.
} 
tions of their children when they received education. Hence, the parents attributed a lot of power to education.

To subsume, the category developing a positive self-concept exhibits different properties. It is defined by a child's ability to help, especially regarding the family, by their permanent effort to study hard, by the feeling of having the possibility to become a valued member of society, by using possibilities to bring about change, by knowing that they are supported by the people surrounding them, and by trying to fulfil - sometimes challenging - expectations of parents and teachers. By listing the most significant properties of this category, it becomes clear that developing a positive self-concept depends very much on the possibilities that the children can identify in their lives and especially in relation to the community. This again can be seen against the background of turning capabilities into functionings, i.e. having/getting the possibilities to reach valuable states of being. Additionally, the degree of involvement plays an important role. The degree of involvement is defined through possibilities of participation and interaction within the school community. The more possibilities can be identified and the more the degree of involvement increases, the more positive the self-concept becomes. Thus, having possibilities to participate at school, in the family life and in the community and having friends and supporters strengthen the children. It supports feelings of equity and equality and adds to their quality of life. Accordingly, the category developing a positive self-concept has consequences (CONS) in terms of new possibilities that open up as illustrated below next to listing the most significant properties.

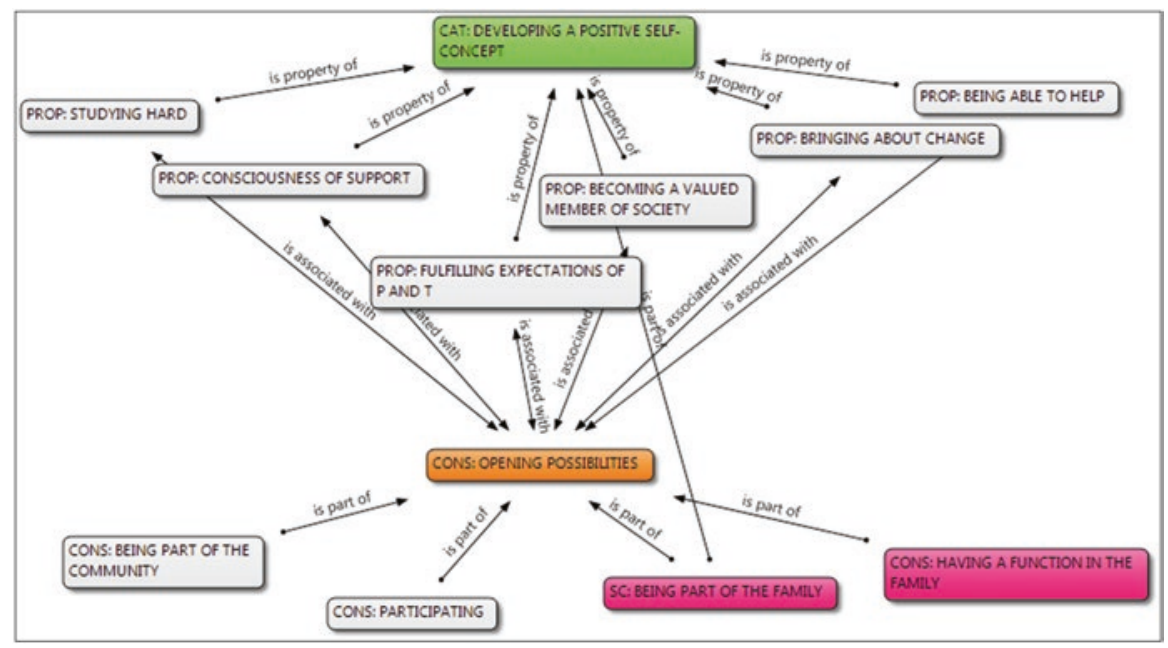

Network View 5.1 Properties of developing a positive self-concept 
This network view gives an overview of the category and its most relevant properties and shows the significance of the family in this context (in pink). The consequence of having certain functions in the family has to be considered as essential, as it was identified as one of the most important aspects by the children. The most meaningful task in this context was to be able to support the parents and family now and in the future as an adult. Another consequence was the aspect of participation. Through the development of a positive self-perception, the children exhibited a feeling of being able to participate in school and maybe later also as a valued member of society. All these aspects resulted in the children's conviction of being able to become a valued part of the community and the family.

\section{Question of Belonging: Struggle}

The question of belonging describes the children's struggle regarding a feeling of belonging. It includes negative aspects that are not included in the former category. However, it also contains positive aspects. It is a moving back and forth between possibilities and restrictions, between rejection and acceptance, between exclusion and inclusion. The children's environment provides them with conflicting input they have to deal with in the process of trying to find their place in society.

The category question of belonging emerged from code families and subcategories that were related to aspects like discrimination, restrictions and concern about the future, as well as different emotions expressed by the children (happiness and satisfaction as well as sadness, worries and anxiety). Furthermore, it included the way in which the children were involved in daily activities at school (morning ceremony, classroom activities, breaktime) but also punishment and teachers' advice, which defined the children's "belonging to school", the role they played in the school community and how they were integrated. In this context, being punished like other children or not is also an important aspect of equal treatment and, ultimately, equality.

The question of belonging refers to the children's position in their society (in the school community, in the community at home, in society in general, etc.) and the difficulties that arise when given the possibilities that education seems to open for the children. On the one hand, they experienced discrimination, exclusion, injustice, restrictions and negative reactions related to their disability. This led to a feeling of inferiority and of not belonging, whether at school, in the community or at home. The negative identification with the disability hampered a positive outlook for the future. However, on the other hand, the positive self-concept of the children proved that an optimistic attitude predominated when talking about education. Nevertheless, the children were aware of the problems that existed and with which they would be confronted (like finding a school or university that was accessible for them, restrictions in choosing certain professions, etc.). 
What is very important for me is that it is only in this school that people have a positive attitude towards us. There are many clubs in this school. We also visit various schools. And when the people who are there see us, they wonder why we came to their school. When we go to the town, mini-bus drivers do not welcome us. But in our school, we participate in many activities. I have no words to express everything. (Erevu, child)

These positive and negative aspects that children with disabilities are confronted with stress the significance of the question "Where do I belong?". The possibilities that education seems to open for them are always clouded by the additional challenges they have to face. Thus, they don't really belong to the school community, as their participation in activities is restricted. However, the children's self-esteem grows as their "attending a school" usually leads to a revaluation of their person in their closer environment and in their families. Consequently, a feeling of belonging to the family and being of value for them starts to evolve and supports the positive attitudes that the children generally have towards their future.

All in all the children were satisfied with their schools. They liked their teachers and they liked to study. However, when asking children about the change they would like to see in their schools, the most common answer was in regard to the cleanliness and neatness of their schools - or the lack of it. They complained about broken doors and windows, wished for classrooms to be painted, etc. "When we were in [the old buildings of] school F, the school was old, the classrooms were old, and the doors were broken. But here, the school is in a new building. So, it is pleasant" (Elisa, child). The children were very critical about these issues. They wanted their schools to be painted, broken doors and windows to be repaired, and toilets to be cleaned. Hence, the possibility of getting education was not satisfying for them in a "no matter how" way. They expressed a strong wish of attending a clean, neat and beautiful school. It therefore became evident that the learning environment was of major importance for the children and their feeling of well-being, which also influenced the teaching-learning process.

The last subcategory that has to be mentioned here is language. Considering the richness of languages in the Ethiopian culture, it has to get special attention. The subcategory started to develop because there were lots of families who had moved to Addis Ababa from the countryside. Therefore, some of the participating families spoke languages other than Amharic, which is used as language of instruction in the lower grades at the schools of the capital. However, none of the participants spoke about problems regarding language. Some explained that they spoke their mother tongue at home, but Amharic in general. Yet, there was one exemption: sign language. Sign language was the most prevalent topic regarding the subcategory "language". It became obvious that this was an important issue because questions of belonging are usually also defined by language affiliations. In other words, one characteristic of groups and communities is their way of communicating. It seems that people who use sign language have a double challenge regarding their place of belonging and integration in society: first, negative attitudes towards their disability 
and, second, problems of communication. ${ }^{8}$ No other challenges regarding language were communicated in the interviews of this research.

To recapitulate, the category question of belonging is connected to the children's feelings of excludedness and includedness, to their possibilities of participation and the restrictions they had to face. This was related especially to the school community but has also to be understood in relation to their position in their families. The attitudes of the people surrounding them played a major role. Discrimination and exclusion are attached to people's negative attitudes towards people with disabilities. But attitudes can change, as will be demonstrated when looking at the parents' perspectives.

By describing how much they liked their teachers, the school and receiving education in general, the children communicated a very positive image of their school environment. Their well-being was influenced by all those aspects (e.g. having friends, playing with friends during breaktime, liking teachers). At the same time, the children were critical towards the school environment. They criticised the school appearance, the teachers and other aspects (e.g. transport to school). "Everything is good in this school. But our parents are tired of bringing us to school and back home. Therefore, it is better if we get transportation services" (Melat, child).

Here again conflicting positions can be identified. On the one hand, the children felt comfortable and were very happy attending their school. They wanted to belong to that school. On the other hand, there were many aspects they would like to change. Furthermore, by not being fully integrated, the feeling of belonging was limited. The following network view illustrates the elaborated properties of the category question of belonging.

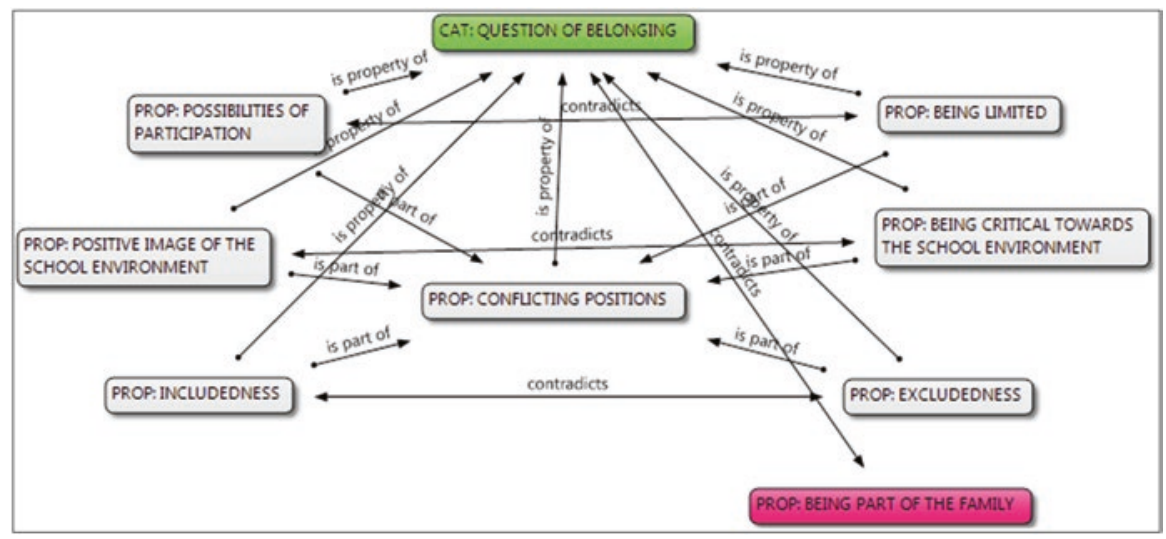

Network View 5.2 Properties of question of belonging

\footnotetext{
${ }^{8}$ The use of sign language and the challenges that people experience in relation to it are worth being analysed in depth. As this is not possible within this framework, it has to be postponed.
} 
The central property in this network view is the "conflicting positions". However, being part of the family does not have a counterpart here (not feeling as a part of the family), as it was not part of the discussions with children. This does not mean that the feeling of not being part of the family does not exist. It just was not addressed by any of the statements made by the children. This can be interpreted in the way that it might be hard to talk about or that it really did not exist as such amongst the participating children. In any case, this question cannot be answered here. It has to be added that in the cases where children had left their closer families, their family was replaced by their extended family or the like.

Throughout the discussion, the significance of education to the children was apparent. Therefore, the following chapter summarises the listed categories and concludes with the meaning of education for the children.

\section{Summary and the Meaning of Education for Children}

The predefined groups of disabilities (physical, visual, hearing and intellectual) do not play an essential role regarding the categories that emerged, with the exemption of the subcategory language, ${ }^{9}$ which is related to the category developing a positive self-concept. The reason why the different types of disabilities did not receive special attention individually might be because the interviews were analysed in groups of participants and not following the individual cases (child-parent-teacher), which would have been more according to the different types of disabilities because the individual child would have been at the centre. However, in the present case, the categories developing a positive self-concept and question of belonging are reflected in one way or the other in all the interviews. ${ }^{10}$

It is in fact not astonishing that the children interviewed exhibited a positive selfperception related to issues of education. Knowing about the background and the meaning which parents, teachers and the society in general gave to education, it became evident that the possibility to attend a school had a positive effect on the children's self-perception. This was especially important as it gave the participating children a feeling of being integrated in society. Simultaneously, the significance of knowledge and learning skills became manifest. The positive self-image can only persist if enough knowledge and skills are acquired to be able to undergo further education, get a good job, support the family or what other wishes the children expressed. This also includes knowledge and skills that allow a person to be as independent as possible and is especially relevant for children with intellectual disabilities. Finally, this leads to the category question of belonging, as the children did have the possibilities to attend a school, obtain skills and knowledge and develop feelings

\footnotetext{
${ }^{9}$ Children with other disabilities (especially PI and II) sometimes also exhibited speech problems. This can lead to challenges similar to those faced by children who use sign language.

${ }^{10}$ This should be further explored in another research to identify differences by analysing cases, not groups, of participants.
} 
of belonging. Yet, they were still not treated equally in society and experienced restrictions, discrimination and exclusion. Therefore, this category is based on the question "Where do I belong?". In other words, the possibility of receiving education did not automatically lead to a change in societal attitudes towards children with disabilities, which would be essential for successful inclusion. However, the same was not true for the families of most of the children. Attending a school often led to a revaluation of the child in his/her family. ${ }^{11}$ Education therefore led to a different perception of the child as a member of the family. This seemed to be true also for the children themselves. Their perception of their possibilities and their values changed by receiving education. The change of attitudes in the society seems to take a comparatively longer time. Nevertheless, a slight change in attitudes and awareness was already visible. This became clear in particular in the parents' interviews.

Regarding societal and cultural aspects, it can be stated that the view that education leads to a better future reflects the attitude of the Ethiopian society as a whole. Education is generally perceived as one of the main aspects for an improvement of life conditions.

Speaking about education thereby is not reflecting quality education or educational equity. It is simply the fact that the children went to a school, like all the other children. They participated more or less in the classrooms and received more or less education. Hence, education in this context is related to the possibility of going to a school and sitting in a classroom. This clearly shows that future developments have to concentrate on inclusive schooling and quality in education (education as a capability) in order to offer children with disabilities equity in education and equal possibilities to participate in society (reaching functionings that people have reason to value).

\section{Listening to Parents and Caregivers}

It became evident very soon that a lot of emphasis was placed on aspects of communication by the parents ${ }^{12}$ and teachers. Communication played an important role for the parents after finding out about the disability of their child. The information that the parents got from doctors, friends, the community and their families was a first basis for them to position themselves and react to the situation. This continued when a school had to be found for the children.

The category related to communication and information finally resulted in the category establishment of knowledge about the child and education. The parents' knowledge about their child as well as about education grew through communica-

\footnotetext{
${ }^{11}$ There were cases where children were orphans or had moved from the countryside to the city without their parents. In those cases, usually grandparents, aunts or other relatives took care of them and substituted their family.

${ }^{12}$ In the following, the term "parents" is used for parents and caregivers alike, as they play similar roles in this context.
} 
tion and information. Furthermore, this category contains a lot of information about the relation between the parents and their children.

Once at school, the parents' attitudes and expectations usually changed. The category the walk of shame reflects this process. "But all in all, we can say that culturally, parents have a negative attitude towards handicapped children. As far as I am concerned, there seems to be a problem in this respect" (Mekoya, teacher). This perception expressed by a teacher might not be applicable for parents in general; however, lots of parents reported a change in their attitudes towards their children, as will be explicated below.

The parents mostly did not have a good education themselves or none at all and did not think they could make any contribution at all to the education of their child. Hence, it became the teachers' responsibility to educate the child and to convince the parents of their abilities and possibilities to support their children regarding education. This is elaborated in detail in the chapter on parental support.

\section{Establishing Knowledge About the Child and Education: Developing Trust}

The key terms in this category are communication and information. Through communication and interaction with the surrounding, parents gain information about their child and the possibilities that education can offer. Additionally, some parents start to discover new potential in their children. Having this knowledge enables parents to develop trust in their child, and it establishes the foundation for future perspectives and support for the children. However, in order to start the process of establishing knowledge, first and foremost parents have to show interest in and care for their child.

In fact, I really don't know what he does in his school. (Semira, mother)

The first impression was that the parents seemed to have little information about their child. However, the information which I asked for in the interviews was largely related to school. The majority of the parents did not know very much about issues related to school. However, they had a lot of knowledge about their children in many other areas. These include the child's personality, relation to God, worries, preferences, feelings, physical condition, desires, abilities, behaviour, problems, disadvantages, etc. Yet, after being informed or having learnt about the child's disability, the parents had to deal with a completely new aspect in their life.

[T] he principal doctor said that my daughter was recovering. She was in the hospital for two days. She received medical treatment and she was well again [...] He explained that she is retarded and that she needs proper care. He went on saying that she walks slowly and eats slowly. He insisted that she should be well taken care of. It was only then that I knew what was wrong with her. I did not know anything about her before she was eight months old. (Mesret, mother) 
Visiting hospitals and doctors became a new occupation for parents if they could afford it. Most of the parents also invested a lot of time and energy in religious and traditional beliefs, according to which disabilities can be healed through holy water and other practices. Only later the aspect of education received more attention. Finding a school for the child was very difficult for most of the parents. Information about schools that accepted children with disabilities was often not accessible for parents, especially if they were illiterate. This information usually depended on people in the surrounding who made the parents aware that there were schools for children with disabilities and that their child was able to learn.

People informed me that there is such a school. They suggested that I should take her to this
school, where she can learn something. They told me that there is some hope for her there
as she will be engaged in some activities. They said that if I keep her in the house, her condi-
tion will worsen due to lack of activity. They also felt that she will be prone to other diseases
if she remained in that condition. Because of this then, I brought her to this school. It is now
three years since she joined this school. (Mesret, mother)

Teachers often also inform their surroundings about the possibilities of education for children with disabilities. Other informants are NGOs or community-based rehabilitation workers. "There was an organization which [...] takes care of the orphans due to HIV/AIDS. When they saw her on their way they told me that possibly she can get into a special school" (Almaz, mother). All this information is accessible for the parents as it is communicated verbally.

The way in which the parents got information at schools differed from case to case. At school some had good relationships with the teachers, particularly in the special units and special schools, and communication was facilitated in a familial atmosphere. Others relied on the communication with the child, and some had hardly any communication at all about school with teachers, principals or their children. Hence, when the latter was the case, knowledge about the school hardly existed. This again was related to the parents' belief that they were not of use for their child in school-related issues, as they were not educated themselves. Regarding exchange with other parents, it was interesting to find out that in every school there was a parent-teacher association (PTA). However, many parents did not attend the meetings for different reasons like lack of time, not knowing about the PTA, etc. Therefore, exchange between the parents of children with disabilities did not take place usually. Additionally, in most cases, the school was not located in the vicinity of the families, and the parents did not know other parents from their community who sent their children to the same school. Yet, the parents of children attending special schools seemed to have more communication with each other than other parents. This could be related to the size of those schools. Special schools are quite small compared to regular governmental schools, which leads to the situation that people usually know each other. Similarly, the special units in regular schools provide parents with better possibilities to communicate with parents and teachers. Here, the already mentioned familiarity plays an essential role regarding information and communication between schools and parents. 
Having sent their child to a school, the parents were often surprised about the changes that could be observed in their children. "Previously, he would run, disturb and damage things. But now, although I wonder whether it is caused by mental development, he has changed tremendously" (Rahel, mother). Many of the parents started to discover the potential of their children, which is connected to the category the walk of shame. Establishing knowledge, however, has further important properties. The parents' interest and engagement, for example, as well as their caring about the child, are essential preconditions for exchange of information and knowledge.

This network view shows the most essential properties of the category establishing knowledge about the child and education. Additionally, first connections are drawn to categories and subcategories of the children's perspective. As the establishment of knowledge is related to caring, interest and engagement on the parents' part, it is related to the child that is perceived as part of the family that has to be taken care of. The aspect of being part of the family is a property of the children's question of belonging. I will further explain connections and relations between different categories during the development of the theory.

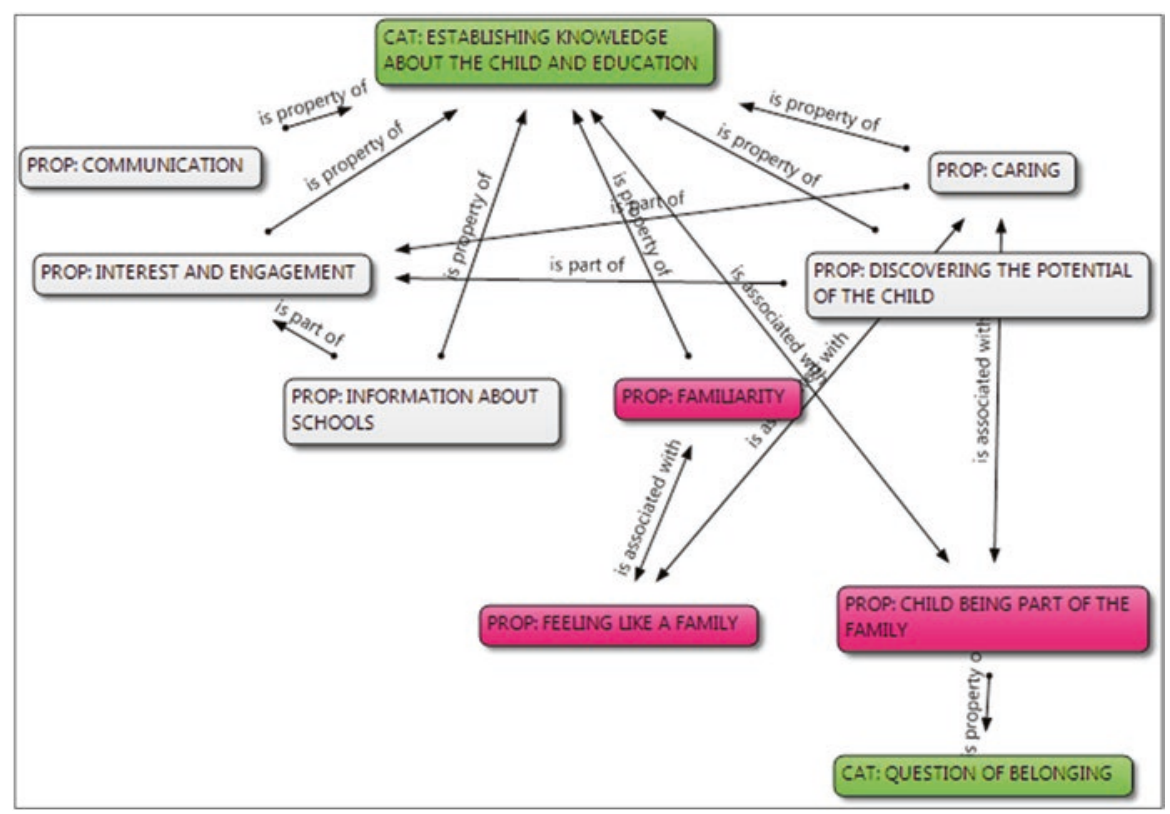

Network View 5.3 Properties of establishing knowledge about the child and education 


\section{"The Walk of Shame" - Towards a Change in Attitudes: Breaking Free}

The basis for this category is viewing disability as a curse by God. It involves feelings of shame and burdens children as well as parents. Education seems to offer a way out of this dilemma and changes the perception of disability. Hence, parents discover the significance of education and possibilities that are opening up. Consequently, they might feel an "atmosphere of departure". They walk the walk of shame when they break free from old convictions and take on new perspectives regarding disability in general and their child with a disability in particular.

I don't believe that disability is a hindrance. I don't think that she will fail to do what others have done. I should bear in mind that there are other people who are in a worse condition than herself. As far as I am concerned, I don't feel bad about her disability now although I used to in the past. (Wongel, mother)

This category contains a more complex process than the ones before. It was therefore considered as helpful to visualise a simplified version of the process in a network view (CAT $=$ category, $\mathrm{SC}=$ subcategory $)$.

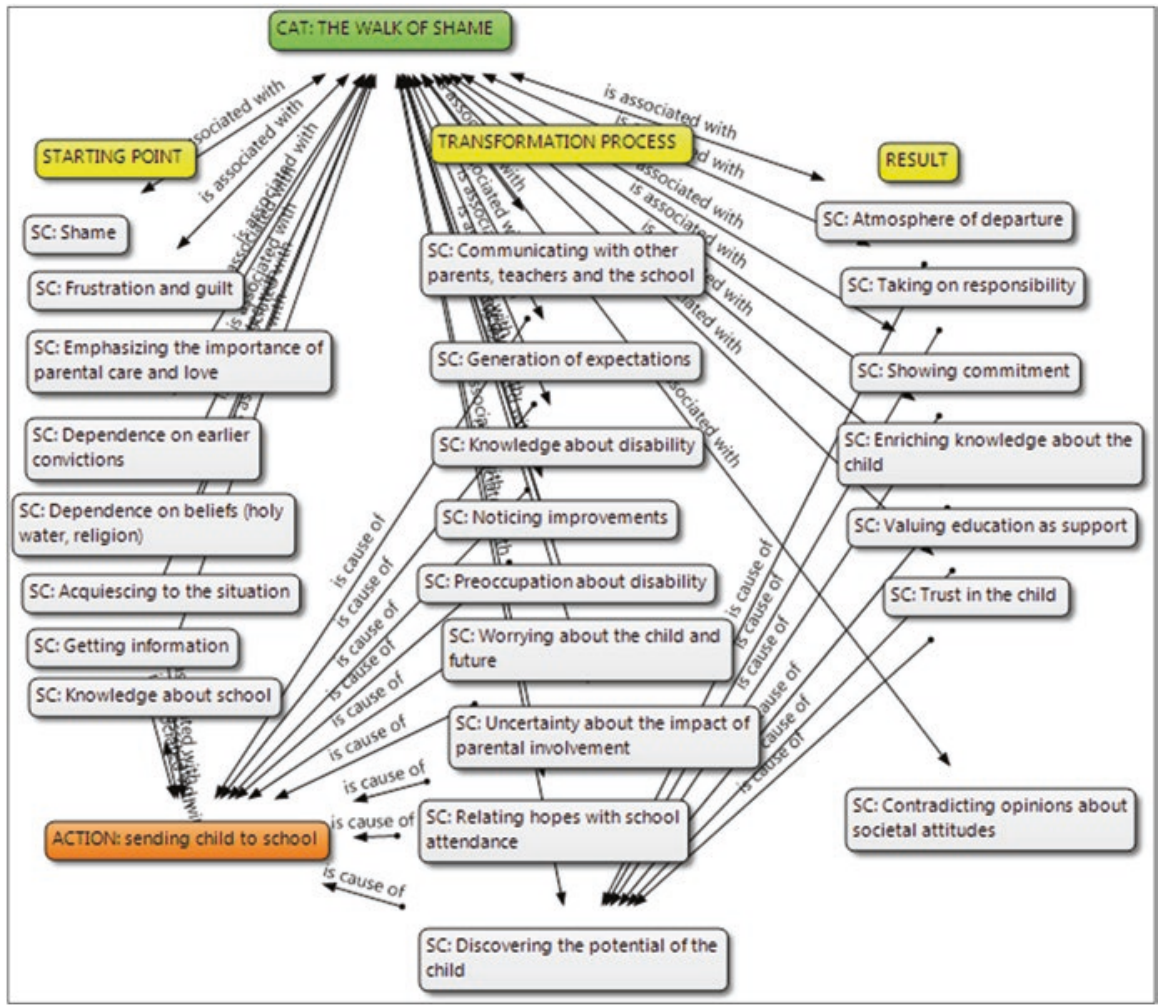

Network View 5.4 The different stages of the walk of shame 
Different stages can be observed in the walk of shame. The three most important ones can be grouped as STARTING POINT, TRANSFORMATION PROCESS and

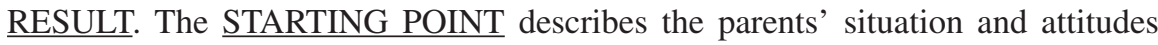
before the child was sent to school. Very often the expectations of parents of children with disabilities were not fulfilled, and they had to deal with disappointments and issues which they had not expected (e.g. various perceived restrictions like communication, support at home, school access). The parents usually considered their children not to be able to learn. The disability of a child can provoke a feeling of shame and guilt in the parents' life. Therefore, especially mothers took on a role of being guilty and tried to change the "fate" of having a child with a disability by, e.g. going to holy waters to heal their child. "When I think about it now, I had a great impact on her. If I had accepted all the problems gracefully when I was pregnant, she might not have become a retarded child" (Tigist, mother).

If parents express grief because of a child's disability, the community might feel pity or try to support the family. On the other hand, as disability is understood as a curse, the community often believes that there is a reason for a child's disability and hence locates the responsibility for it in the parents. This can also lead to a feeling of shame. The reasons for shame are usually created by the society itself. There were contradicting statements about societal attitudes. On the one hand, the society and communities seemed to be supportive and helpful for the families. "Society's attitude towards disabled people is now positive. It is positive here in Addis" (Almaz, mother). On the other hand, there are experiences of insult and scolding: "Mostly I quarrel with men; I told them not to touch him. I lost one of my eyes because of him. I always quarrel with my neighbours again because of him. My neighbours insulted me saying I have this kind of child due to my evil deeds and curse" (Adanesh, mother). Seeing disability as a consequence of parents being cursed or having done something wrong has negative implications. From such a perspective, the disability uncovers a weakness that parents seem to have. This again can lead to loss of reputation and negative emotions attached to the child with a disability or the disability as such. However, these feelings did not seem to persist in the parents. "I didn't expect he was able to learn; just like my eldest daughter. Later on when I realised this I was very happy" (Mersha, father). Additionally, beliefs and convictions prevent parents from being able to see the potential of their children with a disability. It seemed that especially the education for their children led to a change in these attitudes.

The TRANSFORMATION PROCESS already began at the end of the first stage by acquiescing to the situation and getting information about education and schools, which is related to the former category establishing knowledge about the child and education. However, the main part of the transformation process happened when the child was already at school. On the one hand, the communication with other parents and teachers led to a change in attitudes. On the other hand, improvements that were observed by the parents contributed to a positive attitude towards education and the child with a disability. Throughout this process, certain expectations developed on the parents' part. Education gave the parents hope for the future of their children. The initial feeling of shame and guilt turned into hope and higher expectations. Children performed well at school, or they improved in other aspects related to daily life. 
"Some time ago, my son got lost. People found him because he was able to tell the school where he learnt. Education is useful" (Tigist, mother). Hence, the parents started to discover potential in their children which they had not expected. This led to the last stage, the RESULT, which started with a new feeling for the parents: the atmosphere of departure. In other words, the disability of their child was suddenly not only debilitating or producing suffering. There was a way to go, a solution, a new goal to reach that led to a benefit for the children as well as for the whole family. Therefore, the parents started to take on responsibility and show commitment regarding the education for their child with a disability, whereas before uncertainty about the impact of their involvement in educational issues had prevailed. They supported the child and distanced themselves from old beliefs of guilt and shame. As a consequence, their knowledge about the child was enriched, and education was valued as support and constructive input. This is also related to the category establishing knowledge about the child and education. Viewed in this context and from the perspective of the capability approach, education can be interpreted as a capability that can lead to certain functionings in life (independence, jobs, etc.). It seems that the parents experienced the possibility of education for their children as such a capability. However, this capability only exists because it was enabled through a first step towards educational equity. This means that equity in education starts with equal possibilities to receive education, i.e. access to schools. The basic capability for education is the ability to learn. Being able to learn, getting the possibility to access school and receive (quality) education finally leads towards more possibilities in life and hence functionings that are valued by the individual as well as society. This improves the children's as well as the parents' well-being and quality of life.

The parents trusted that their children were able to learn and that they might even be able to support the family in the future; in other words, that they were growing up to become a valued member in the community. Hence, the category the walk of shame describes the process of change in the parents' attitudes from being ashamed and burdened with their child's disability towards being proud and having future prospects for the child and his or her family. There is a close relation with the category parental support as well as with the children's category question of belonging. The parents' acceptance of the child and the value which the children gained through education strengthened a feeling of belonging to the family. Furthermore, it supported the children's category of developing a positive self-concept.

Communication with CBR workers, teachers, other parents, etc. about the problems that the parents experienced led to more information and knowledge about disability in general.

Most of the parents believed that there was still a reason why their child had a disability and that it was the will of God that put them in this situation. However, it was no longer perceived as a burdensome situation. Parents who sent their children to school developed certain new attitudes and spoke about disability as "nothing", meaning that their child could be a part of society and contribute to the community. In this way, disability did not mean anything. As soon as their child attended a school, the parents were convinced that the child was able to learn. The possibility of education for a child with a disability alone changed the attitudes of his or her parents. In this context, the fact that teachers and principals accepted their child played a major role. Before, negative atti- 
tudes on the part of the society and the surrounding community had often influenced the feelings and thoughts of parents regarding disability to a great extent.

The most important properties of the category the walk of shame are first and foremost the possibility and readiness to change an attitude. Especially in a society where attitudes towards people with disabilities are mostly charged with feelings of pity, shame and guilt, it is not easy to take on a different position. This is true in particular in cases where the community has a big influence on the lives of the people. "I usually cry saying why God gave me this thing. The people also comment 'what did they do', so I just keep crying. But thanks to the Almighty God, he spends his time at school" (Liya, mother). Nevertheless, the parents seemed to distance themselves more and more from such comments and develop different viewpoints: "People used to say that the evil thing they did is why they have dumb and deaf children. However, parents have handicapped children not because they are cursed" (Agnes, mother). Access to information and environments for discussion can be regarded as further properties of the category as well as the feasibility of combining the new attitude with old convictions (from e.g. religious or other traditional backgrounds). Breaking free from assigned accountability for a disability requires support. This support can be attained through discussions, exchange and information but also by experiencing change through education.

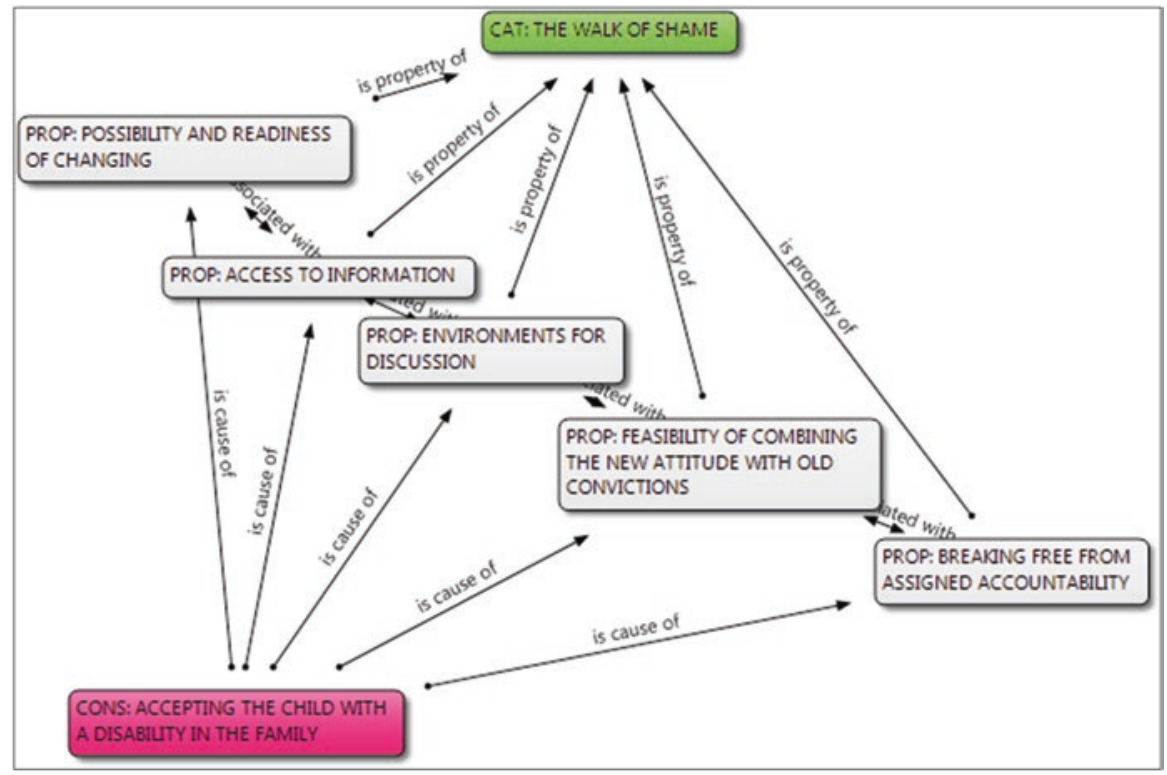

Network View 5.5 Properties of the Walk of Shame (This network view only contains properties that have not been listed as a subcategory before. The level of abstraction has grown compared with the other categories at this stage of analysis. Only the category question of belonging has reached similar levels of abstraction. The researcher attempts to reflect the process of developing a theory as it actually took place. This includes depicting the stages of each category individually. Hence, the aim to unify these stages exists only up to a certain level to make it convenient for the reader. The reason for the different levels of abstraction is related to the process that the researcher went through in the course of the analysis) 
Most of the parents exhibited a certain "walk of shame". For some, it was harder than for others, and it might have taken more time. However, parents who did not feel ashamed of their children with disabilities usually had more information about disability in general before they learnt about the disability of their child. Another important factor was the communication with the child and the possibility to communicate. Hearing-impaired children were often considered as "dumb", as the possibility of communication was usually limited. This connects the topical category to the category establishing knowledge about the child and education, as mentioned above. Hence, communication and information becomes a factor for counteracting shame and guilt.

\section{Parental Support: Departure}

The most important aspect in this category is the aspect of responsibility that has to be taken on by the parents. Furthermore, parental support is influenced by fears and worries, awareness, possibilities and efforts on the parents' part. All these aspects lead to the different areas of support that parents do or do not give to their children. However, the possibilities that open up through the help of parents for the children add to the atmosphere of departure that is evoked by the parents' walk of shame. If parents support their children in education, they contribute to their departure towards their new possibilities.

I prepare his uniform in the evening. In the morning, he says that he does not want to go to school. He has other brothers, whom I have to see off to school. Then, it is already 9 a.m. when I have to beg him to go to school. I have a hard time with him, but I can't help it because I feel that nothing else is more important to me than my son. (Felekech, mother)

As already indicated in the chapter on children's perspectives, parental support has a lot of influence on the child and his/her self-perception. The relation between the two categories developing a positive self-concept and parental support is further explicated later.

The category parental support started to develop as a code family including codes on worries and fears that were grounded in the parent's interviews. Hence, the category was elaborated by exploring the different worries that parents had and how these worries and anxieties were reflected in the support that parents did or did not give to their children. An example of this process is reflected in my following memo:

There are different types of parental support.

A very important one is the support that parents (caregivers) give to their children when it comes to the way to school. Children say 'she protects me' (Semret, mother) and most parents talk about how to support their child so he/she gets save to school. Some parents go with their children, stay at school and go home with their children; some only take them and pick them up again; some send them with friends or siblings, so they don't have to go alone. 
The fears that the parents are telling us about are first of all related to the transport and traffic. This is due to the problems that the children exhibit because of their low vision, hearing or other restrictions in body functions. It is not really clear if parents would be as worried about their children who don't have a disability. (Memo 22/11/2012)

In addition to worries and fears, parental support is determined by other aspects. These include beliefs and convictions, attitudes, possibilities, the surrounding environment, etc.

However, in a first step, it has to be clarified that "parental support" is everything that parents define as support. In other words, it means getting active for the child and investing time and other resources. Support can be understood as everything that parents believe helps and supports their child, regardless of the effect it has.

The category parental support can be divided into six different types of support:

- Health and disability: visiting doctors and holy waters

- Independence in daily life: teaching cleanliness, house chores, etc.

- Studying environment: finding a school, supporting studies at home, transport

- Studying at school: getting involved, attending PTA meetings, communicating with the school and teachers

- Encouraging the child: giving self-confidence, being proud, having hopes and expectations, changing attitudes, believing in the child

- (Not being able to support the child: feeling helpless, not having time, illiteracy)

These types of support can also be observed in a process that is similar to the change of attitudes in the category the walk of shame. First support is related to expectations of healing and to dealing with the situation, and only later it is related to education.

Regarding the chronological development, the aspect "health and disability" stands first. Visiting doctors and going to holy waters for healing were usually the first measures reported by parents in order to support their child, as many parents took on responsibility for the disability. Furthermore, they tried to support their children in becoming independent. As many of the parents were illiterate, the first aspect in this regard was independence in the daily life. Formal education did not play a role at this stage. Only later, parents also started supporting the child in regard to education, as it promised further independence for the child. This already included the decision to send the child to school. Finding a school for their child and organising transport were the two aspects that were identified where parents invested the highest efforts to support their children. The parents were very worried about their children getting lost on their way. This problem was connected to the fact that schools that accepted the child with a disability were usually not in the neighbourhood of the communities in which the families lived. ${ }^{13}$ This resulted in ways to school which were by and large longer than they are for children without disabilities. Consequently, some parents stayed in the school - as mentioned in the memo above - or in the surrounding of the school until school ended, as going to school twice a day to take and pick up the child was in some cases not affordable due to the

\footnotetext{
${ }^{13}$ This circumstance led to further complications: the parents usually did not know other parents at school from the community, they did not benefit from getting involved in educational matters in the community by sending their child to the neighbouring school, etc.
} 
transportation cost. Further support was identified in relation to education at school. Parents got involved in school related issues only on a very low level. However, a difference could be observed between literate and illiterate parents. Literate parents considered themselves more able to support their child in school related issues. The dread of some (especially illiterate) parents to get involved in such issues could be overcome by communicating with teachers but also with children. Thereby, the parent-teacher association (PTA) of each school played an important role. In regard to the parent-child communication, it was interesting to see that if parents were called, sometimes children insisted that they really came to school. This kind of communication also shows that at times children have the power to influence their parents.

If the school sends a note to me asking me to come, but I fail to report, she refuses to go to school. She says to me, 'You have been asked to come, not my sister.' And then, she starts crying. But when I react to that saying, 'What will you eat if I don't work?' She replies to me, 'I won't eat. I only want you to come to school.' Even today, she said to me, 'Berhane [the teacher] wants to see you.' I came today because she insisted. When she saw me here, she happily went to class. (Wongel, mother)

This reveals that in some cases children took on the responsibility for their education and familial support. By having children in such a position, also illiterate parents who were not involved in educational matters at school could be informed step by step about their possibilities to support the child in education. Others were keen to support their child in any way they could from the outset and considered it as a right that they had. "What does the school expect me to do? If there is anything, I have the right to participate using my potential" (Abraham, father). Whether parents supported their child or not was furthermore closely related to their possibilities and time resources. The explanations of parents who did not come to school often and did not get involved very much in school-related issues were related to time constraints because of having to earn the daily bread or being involved in other daily activities at home, ${ }^{14}$ etc. "I know nothing about education. If I had some knowledge about education, I could ask about the performance of my son. I should also do this but I am so busy to get my daily bread" (Semira, mother). Another factor related to time was the parents' fear of what would become of their child when they died. "Besides, I also help him as much as possible. If he gets support from the school, it is my obligation to help him at home. But my fear is that I might die soon before he achieves success. I don't think I will stay long in this world because I usually get sick" (Fatima, mother).

The support that the children received in terms of education also included encouragement. This point might be one of the most important ones for some children. Most parents were happy about the achievements of their children. However, there was also disappointment in cases where the expectations were higher than the achieved results. In these cases the parents had mostly hoped for improvements regarding the child's disability. This was especially visible in relation to the children identified as having an intellectual disability.

\footnotetext{
${ }^{14}$ Concerning this point especially, the financial compensation for the interviews was very important.
} 
Y Were you following her up before that?

$\mathrm{Me} \quad \mathrm{I}$ was. The teachers are right. She has gradually gone worse. I am disappointed. All my efforts are in vain. (Mesret, mother)

Parents usually had great hopes as soon as their child attended a school. These hopes turned into expectations and were as such easily disappointed. "Others say that they have not seen any change. If we don't see any improvement in spite of all the time that we have invested, we get disappointed" (Rahel, 2E-II-D-8-GIP). Yet, lots of parents were proud of the achievements of their children. They believed in their children and developed positive attitudes towards education in cases where they had not already known about the child's abilities related to educational achievements before. Furthermore, education seemed to develop to be one of the most important aspects for the parents in regard to the future of their child with a disability. It was the key for escaping poverty and having the chance to live a better life. "I don't let him stop schooling. I know how difficult it is not to be educated" (Semira, mother). This shows that the parents' awareness of the importance and possibilities of education was sometimes already there before the child was sent to school. However, mostly it developed with the child attending school.

The last type of support was "not being able to support" the child. This constitutes the counterpart to the aforementioned types of support. Here, the feeling of helplessness because of illiteracy, lack of money and other means was as hindering as time constraints.

Within the category of parental support, three dimensions ${ }^{15}$ could be singled out:

- Time

- Energy

- Money

The first two dimensions were applicable for most of the parental support. The third dimension "money" was not always needed in relation to caring for the child. This would indicate that poverty is not decisive regarding parental support. However, the dimension of "time" could be identified as the most significant one in relation to the parents supporting their children. And this again is connected to the dimension of "money". Most of the parents reported that they were too busy to support their children adequately as they needed to earn their income. Furthermore, the parents felt guilty for not being able to help their children more: "If they ask me to leave my job even for one day, I can't do it. What I have to do is that I have to work everywhere; when he returns home from school I have to feed him properly. Other than this I'm afraid I can't help him" (Semira, mother). Hence, the dimension of "time" determines the extent of support which the parents could give to their children.

The following network view gives an overview of the category including its most important properties.

\footnotetext{
${ }^{15}$ Dimensions are always measurable extents or quantities. The researcher mentioned in the earlier footnote number 46 that dimensions cannot be applied to all of the categories. However, in the case of parental support, different dimensions could be identified clearly.
} 


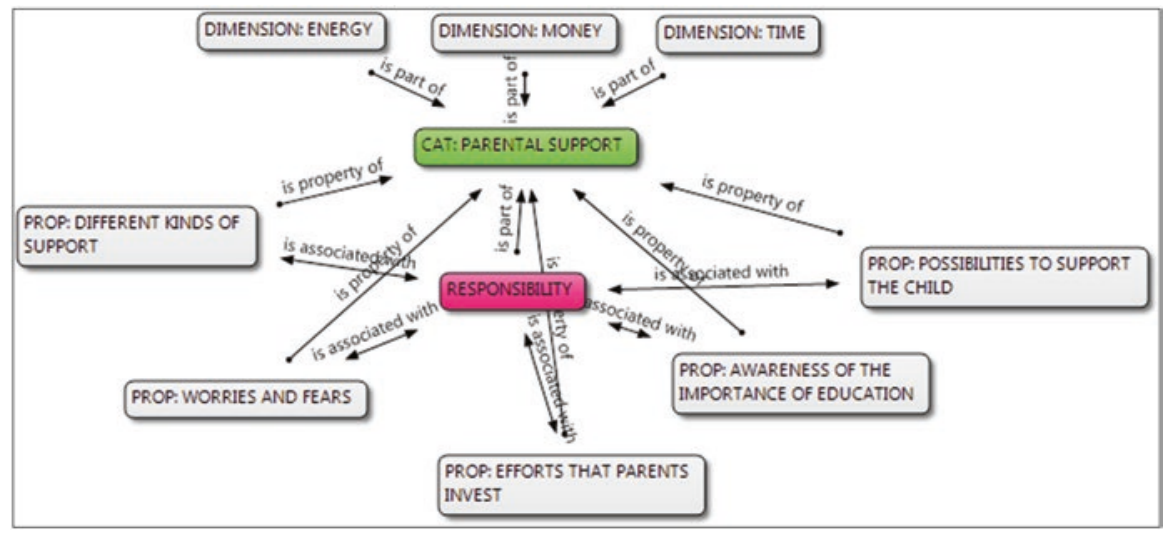

Network View 5.6 Properties of parental support

The analysis showed that the category of "parental support" is strongly related to responsibility. Responsibility can be understood as taking on responsibility for the child's disability, being responsible for the child or being overburdened by taking on responsibility. Furthermore, without any feeling of responsibility there would not by any kind of parental support. In this way, responsibility was the motor for the parents supporting their child. In this context, one exception has to be mentioned. Religious beliefs were sometimes also a reason for supporting the child. One parent stated that she was afraid to be punished by God if she would not support the child properly. This indicates that it is also the will of God that parents care for their children with disabilities. However, responsibility as a motor for support can have positive effects (enhancing support) as well as negative effects (not feeling responsible and hence not supporting the child).

\section{Summary and the Meaning of Education for the Parents}

The three categories establishing knowledge about the child and education, the walk of shame and parental support share one essential aspect: responsibility. This aspect became relevant in all three categories. It was a prerequisite for establishing knowledge as well as for changing attitudes and for supporting the child. Without a feeling of responsibility (and possibilities) for influencing and improving the future life of their children, the parents would not go through the mentioned processes. Thus, communication and information shaped the parents' views of their children and influenced the development of responsibility as regards education.

My son encountered hearing problems when he was two years old. Before that he could hear; his problem is the result of meningitis. I have never thought of getting educational opportunities for him. When he grew up, people informed me that he could learn in a school 
where disabled children attend. The moment I heard about this I was really happy. My worry was what would happen if he was deaf and illiterate and stayed at home for the rest of his life. (Mersha, father)

The parents' worries were usually about the children's future. In this context education played a significant role. However, in the focus group discussion in school $\mathrm{C}$ during the second phase of interviews, it became clear that the school was considered much more than just a place for education. The parents expressed their worries when their children were in the village. They spoke about them being insulted, beaten and not respected. In the school, the parents felt that their children were safe and could not get on the wrong track. In other words, they were looked after and would not develop bad habits. Hence, school assumed the role of supporting the parents. The parents believed that education established a strong foundation for the future lives of their children. Furthermore, education enabled the children to care for their family.

Regarding societal and cultural aspects within these categories, the aspect of caring for the family can certainly be mentioned. On the one hand, it was a relief for the parents to be able to see their children attending a school like other children. In this way, the children were integrated at school to a certain extent and new possibilities started to open for them. Consequently the parents discovered future perspectives for their children. On the other hand, education served children with disabilities to be able to support the family in the future. In other words, education led to a better integration of the children and hence to relief for their parents and provided the children with future perspectives and capabilities that might serve their family and also disburden their parents. Education therefore can be understood as support for the parents and family as it takes a lot of worries and pressure from them.

An important cultural aspect was the one of religion. The people in the interviews turned out to be very religious and give a lot of meaning to their beliefs. Even though there are several religions, Christianity and Islam are the predominant ones in Ethiopia. The participants were all either Muslims or Orthodox Christians. God was always referred to as the one who decides, as the one who gives and takes and as God the Almighty. Lots of parents thought there must be a reason why God decided to give them a child with a disability. In some of these interviews, obvious contradictions could be observed. Belief was not coherent with the later explanations of parents that disability was not related to God or religion at all. This indicates that even if parents learnt about and explained the reasons for disabilities, the belief in a deeper meaning of the child's disability was very strong. The coexistence of both convictions did not seem to cause problems. This point is also strongly related to the property "feasibility of combining the new attitude with old convictions" of the category the walk of shame.

The question of equity and justice was raised in relation to two aspects: First, parents discussed and also questioned the belief of divine justice in relation to having a child with disability. Second, most families aspired equity for their child with disability through the possibility of receiving education and educational equity. The latter again is referring to achievement, fairness and opportunity in education. 


\section{Listening to the Teachers}

For this chapter, it is important to recapitulate that the schools of the sample can be divided into those with a special setting ${ }^{16}$ and those with an integrative setting. Special setting refers to a special school or a special unit (classroom(s)) within a regular school. In the following, they will be called schools with a special setting. In this setting, the children in the classes usually have the "same kind of disability" (categorised by teachers or doctors). In schools with integrative classrooms, ${ }^{17}$ between one and three children with different disabilities attend a regular classroom together with children without disabilities. In the following, they will be called schools with an integrative setting.

As mentioned in the previous chapter, the communication between teachers and parents was often identified as a problematic aspect in the teachers' interviews. This led to the development of different code families and subcategories that were related to the way of exchanging information between parents and teachers and communication in general. The category that emerged from this analysis is called establishing relationships. Another category that was identified is related to teacher education. Lots of problems raised by teachers were grounded in the need of teacher education. This in turn is related to the second category quality of education in the schools. Last but not least, commitment and motivation was discovered as the most important category related to the teachers' interviews; it was the most important because compared with other categories it reflected more various aspects that were considered as essential regarding the education for children with disabilities. In other words, it was the "richest" category related to teachers.

\section{Establishing Relationships: Investing in Working Atmosphere}

This category is about building a basis for teachers to cooperate with parents in a way to be able to support the children. Conflict and trust between parents and teachers both play important roles in this context. Teachers often complain about parents who do not cooperate in the way they would expect it. Establishing relationships therefore can be seen as an investment by teachers to improve their working atmosphere with the children. An important aspect is the feeling like a family that refers to special relations between teachers and parents mainly in special settings.

[...] [I]f the teacher discusses with the student or parents, he can solve the student's problem. Moreover, if parents inform teachers about the problem of their child, his problem can be solved $[\ldots]$ in the school. Similarly, if the problems of the school are communicated to parents, parents may solve the problems of their children to improve their behaviour. Therefore, to make students clever in schools, I believe that parents and teachers should get together regularly and have a good relationship. (Kadhi, teacher)

${ }^{16}$ Four schools of the sample (C, D, F, G).

${ }^{17}$ Three schools of the sample (A, B, E). 
The category of establishing relationships is mainly related to the communication with parents, even though communication with children also played a role in the interviews. However, the subcategories that developed in relation to communication involved parents only. One observation in the teachers' interviews showed that in schools, the communication between parents and teachers was not really enough. "We need information from parents more often. We want to know their [children's] improvements daily. What we do here, in this school only, is not enough. All of us if we don't cooperate and work together, we do not bring any change" (Abkale, teacher). Furthermore, the teachers complained about parents not coming to school when they were called; the teachers did not usually call the parents except when there were problems which they could not solve by themselves. But since mobile phones had reached such a high degree of distribution also amongst the poor population, the possibility to call parents or text them on their mobile phones facilitated the communication between parents and teachers tremendously. ${ }^{18}$ The teachers also expected the parents to support their children. "We would like parents to encourage their children to engage in vocational work. But we don't expect any support from them regarding our teaching profession. We want them to be self-reliant and not to expect anything from the government and the school" (Abeba, teacher). This is a clear statement indicating that teachers did not see the parents' responsibility in any teaching related issue. Besides, the teachers saw problems related to their own responsibility: "In reality, there is a weakness on our part too. It would have been good to know how she [a student] studies at home and how she lives. But I never asked such questions" (Biniyam, teacher). The parents in turn were generally very content with teachers and also with the level and frequency of communication with them. Hence, a differing perception of the situation regarding exchange could be observed between parents and teachers. This might lead to conflicts. The teachers also identified potential areas of conflict:

\begin{abstract}
If students who join grade one often come from a poor family, it will be difficult for parents to fulfil the needs of their children. This, in turn, can create conflict between the teachers and the students. The students don't have exercise books and pens. Besides, they fail to take good care of the materials they need for school. And if we insist that this has to be done, conflict might arise between the children and their parents. (Yemenushal, teacher)
\end{abstract}

In this case, the teacher was also aware of the risk of creating conflict between family members. Without sufficient communication, such problems could lead to difficult situations. An interesting point that arose within the topic of communication was the attribution of "family". This was used more by teachers from special settings but also by the ones in inclusive settings. The teachers repeatedly described their communication with parents in family-related terms.

Y: How do you work with parents?

A: With parents? We are just families and they proved this on different meetings we had. We know each other with every family. When their students misbehave they come

\footnotetext{
18 "Similar to industrial, newly developing and other so-called developing countries, the use of ICT devices in Ethiopia, such as mobile phones, computers, etc., has risen substantially within the last 15 years" (Schiemer and Proyer 2013, 102).
} 
straight to us and tell us everything such as if they [the children] come very late at night, and when they steal their money, everything. [sic] (Temesgen, expert and teacher ${ }^{19}$ )

Additionally, teachers who did not communicate very much with parents in some cases talked about the child with a disability as a family member. This mostly happened in the integrative settings and hence in bigger groups and classes: "By the way, I don't want to call parents to school. I take my own measure. First I warn him and if it is worse I beat him myself. ${ }^{20}$ This is because I consider my students as my own children" (Kadhi, teacher). The attribution of family meant on the one hand taking on responsibilities like in a family, which obviously includes taking disciplinary measures. On the other hand, it implied a familial atmosphere and trust between parents and teachers. In this way, family meant supporting and helping each other as well as mutual understanding. Beating a child was also considered as supportive for the child by the teacher, as it seemed to lead to an improvement in behaviour from the teacher's perspective. However, it is important to mention that children did not talk about the school in such a way. When talking about their family, they never included teachers or school staff. It is clear that children put the focus on supporting their families in the future, which did not include teachers. In the children's interviews, aspects mentioned in relation to school were always education, studying, friends and ideas about their future occupation.

Teachers with commitment wanted to support the students and their families. To be able to do so, information and communication were an essential basis. In some cases, however, it was not easy to get the information needed.

Some other parents do not tell us their problems. Some say that they did not come to school because of shortage of transportation. Some others say that they come from a distance of 30 to 40 kilometres, that is, from Sebeta. Some come late to school despite the fact that they live in the vicinity. All sorts of reasons are given. (Belte, teacher)

The communication within the school differed mostly depending on the setting. The smaller schools and classes (usually special settings) showed closer relations amongst teaching staff and principals. However, this could also be observed in one integrative setting in school $\mathrm{E}$, where the principal showed a lot of commitment and the teachers felt supported.

Communication establishes relationships, which can lead to solutions for various problems. Yet, the teachers had a two-sided attitude towards the necessity of communication regarding the parents. On the one hand, they complained about parents who did not go to school even when they were called. On the other hand, they preferred to solve problems by themselves. Hence, the degree of involvement that was expected of parents was not always defined clearly by the teachers. The following network view gives an overview of important properties of the category.

\footnotetext{
${ }^{19}$ The expression "expert and teacher" is used for differenciating special needs experts in schools and headmasters from teachers without such an additional role.

${ }^{20}$ Physical punishment is not allowed anymore in Ethiopian schools. Nevertheless, some teachers still use it as a disciplinary measure.
} 


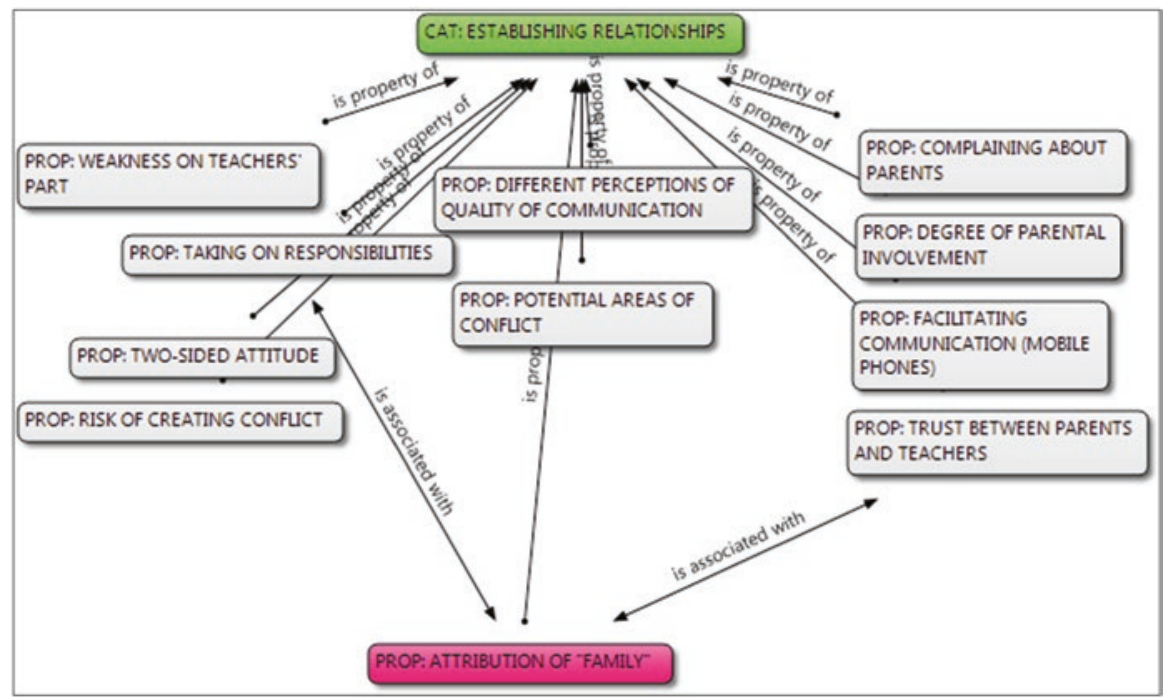

Network View 5.7 Properties of communication (establishing relationships)

The left-hand side of the network view is only about teachers, whereas the righthand side is about the teachers' relationship with the parents. The part in the centre is about parents and teachers. This illustration shows that the relationships between teachers and parents were very unsteady. On the one hand, there were feelings of family in some cases; on the other hand, parental involvement was considered not to be enough. And again in other cases, the teachers preferred not to involve parents too much in school-related issues. It did not become clear which degree of parental involvement was considered to be the best for the children and their education.

However, establishing relationships in general can be seen as a resource that serves the education for children with disabilities. Hence, also relationships and communication between teachers but also between teacher and child are essential resources for the teaching-learning process. Resources also play an important role in the next chapter.

\section{Quality of Education: Needing Support}

The category quality of education refers above all to the support that teachers need in order to be able to improve the situation for children with disabilities (as well as for children in general) at school. It deals with teacher education in terms of teachers' frustration due to a lack of teaching methods and material as well as with the resources that teachers themselves use when teaching children with disabilities. 
I am trained in a special needs college. But it doesn't give me full capacity to help such students [with disabilities]. A teacher who specialises in one area can't manage everything. The course which I took in special needs is another thing. If I don't include my creativity, it wouldn't help me in all aspects to handle problems. Students with such problems must not be trained in such a school which has not enough facilities. All of their teachers must be well trained and well equipped. (Emayu, teacher)

As far as the aspect of teacher training regarding the management of inclusive classrooms is concerned, all the teachers asked for more training. The Ethiopian government initiated a mandatory special needs course in the teacher training colleges through which all teachers received an introduction into special needs education (Alemu Aberra, ${ }^{21}$ expert). This course is not very extensive, and the interviews with teachers showed that it gives insights into causes of disability and focuses on a medical model rather than providing teachers with tools for classroom management and teaching methods and adding the perspective of different models of disability (e.g. the social model). The problem of quality in teacher education was also addressed in the interviews with experts from outside the schools including the interviews with the Minister (see in the chapter on experts). However, the category quality of education refers to the education for children with disabilities, which is strongly related to the quality of teacher education. In this regard, the parents did not see a problem related to the qualification of teachers. In most cases, they were very happy about the teachers' skills, and they even argued that the teachers had more potential in dealing with their children than they themselves. Hence, teachers are highly valued by parents. However, in general teachers do not have a high value in society, and their payment is low. Additionally, the teachers themselves felt overwhelmed by many challenges that they had to face. Here it could be argued that from a capability approach perspective, the capabilities of the teacher to teach well are not supported to reach the functionings to really teach well. In other words, the conversion factors that would turn the capability to teach into a functioning are not applied enough. A conversion factor in this context would be, e.g. teacher training.

However, a lack of teaching resources, the high number of students and a lack of knowledge often led to frustration amongst the teachers. Additionally, they realised that they would need more training in some aspects like methods of teaching and integrating children with disabilities.

There are many things I feel I lack. For example, I would appreciate if somebody like you, who is an expert in special needs, observes how I teach and tells me that I have to develop this skill or that. But I face reality by myself. I apply the methods I was taught. Earlier, there used to be a foreigner from whom we learnt many things. So, we try to apply that. I strive to do as best as I can. (Abkale, teacher)

Then again, the interviews revealed many resources that can be attributed to the teachers and that were used for solving most of their problems. Amongst them were communication with others, becoming active, having confidence, having additional knowledge, having positive attitudes, etc. "Yeah, in here ah, just we shared ahm, there is an experience sharing, we share experiences with each other. [I: Between teachers?] Yeah, teachers with teachers or, that's good for, for us, for new teachers

\footnotetext{
${ }^{21}$ Head of the special needs department at Kotebe College of Teacher Education in Addis Ababa.
} 
especially [...]" (Mamite, teacher). Other resources included the teacher's awareness of the child's problem, seeing the child as an individual and discovering resources in the child. These resources often became visible through the child's improvements, development and positive impressions that the teachers had of the children. In other words, the teacher's knowledge about the child can unveil hidden resources. Of course, the quality of education is closely related to the teacher's competencies. However, children's and parents' resources can also contribute to a good quality in education and support the teaching-learning process.

A surprising aspect was the fact that many of the teachers reported that it was not their first choice to become a teacher. The following quotation is a special one as the interviewed teacher was blind. She was one of the teachers who had a disability and was interviewed in the course of this research. Other teachers with disabilities were only found in schools for hearing impaired students. There most of the teachers had a hearing impairment. ${ }^{22}$

No, if I were not blind, I would not have become a teacher; you see our destiny is quite limited, not like you the seeing; we have few alternatives including sociology, law or teaching; I think I will change [my profession] in the future. At the moment, what is available is a diploma programme in teaching; yet in the future I have plans to change my field. (Belte, teacher)

This blind teacher clearly stated that it was not her choice to become a teacher but that it was due to few alternatives. Further reasons were given by other teachers: "Generally, this [becoming a teacher] was an option in the place where I was living. Since I didn't have a job for a year, I hate being jobless. At that time there was a vacancy announcement looking for teachers whereupon I applied there even though my interest was to be a nurse" (Alem, teacher). These quotations show that a lack of possibilities restricted these teachers in choosing the profession they wanted. This can also have consequences on the quality of the teaching-learning process. Nevertheless, some teachers liked certain aspects of teaching despite not having chosen it in the first place. "The salary is low. I never thought I would be a teacher. In addition, I don't know what I will be in the future. It gives you pleasure to see the children changeas you teach them. But I don't like it as a profession" (Biniyam, teacher).

The teachers also talked about the challenges of being a teacher: "We also teach them slowly since they lack knowledge of the subjects they learn. We also use various teaching aids to enhance their understanding of what is taught. We try hard to help them. So, teaching is a demanding job" (Yemenushal, teacher). This demanding job needs support in lots of aspects, especially in cases where a lack of material and teacher education complicates the situation. Therefore, the teachers talked about different areas where they needed support:

- Cooperation at school (with other teachers and administration)

- Solutions regarding restricted time (workload) and number of students

- Material (regular textbooks as well as special material for teaching children with disabilities)

\footnotetext{
${ }^{22}$ It would be interesting to analyse how the statements of teachers with and without disabilities differ from each other and to what extent. However, this would go beyond the scope of this book and is recommended for a separate study.
} 
- Knowledge and information about children from parents about disabilities (reasons of the disability, possibilities of rehabilitation, etc.), and about special needs education (including Braille and sign language)

- Motivational support (in cases of feeling frustrated and overburdened)

B: We haven't got any training in special needs.

$Y$ : So, how can you help her?

B: There isn't any special support that I can give. In a classroom where there are sixty students it is rather difficult to properly follow up what students are doing. So, the way things stand, it is impossible to give special assistance to an individual student. We teach twenty-four periods per week. Perhaps, we have only two free periods. Being as it is, it will be difficult to give individual attention to a student. (Biniyam, teacher)

Hence, the quality of education for children in general and for children with disabilities in particular depended on various factors. From the teachers' perspective, there was a clear need for support regarding special needs education. In other words, they needed tools to be able to manage classrooms with integrative settings as well as with special settings. Therefore, they needed special training, information from the parents (communication) and support material. Furthermore, most classes were too big in terms of the number of children. All of these aspects limited the quality of education for the children with disabilities. Last but not least, motivational issues and teachers' commitment played an essential role. This will be discussed in the next chapter. The following network view gives an overview of the most essential properties and essential aspects of the category quality of education.

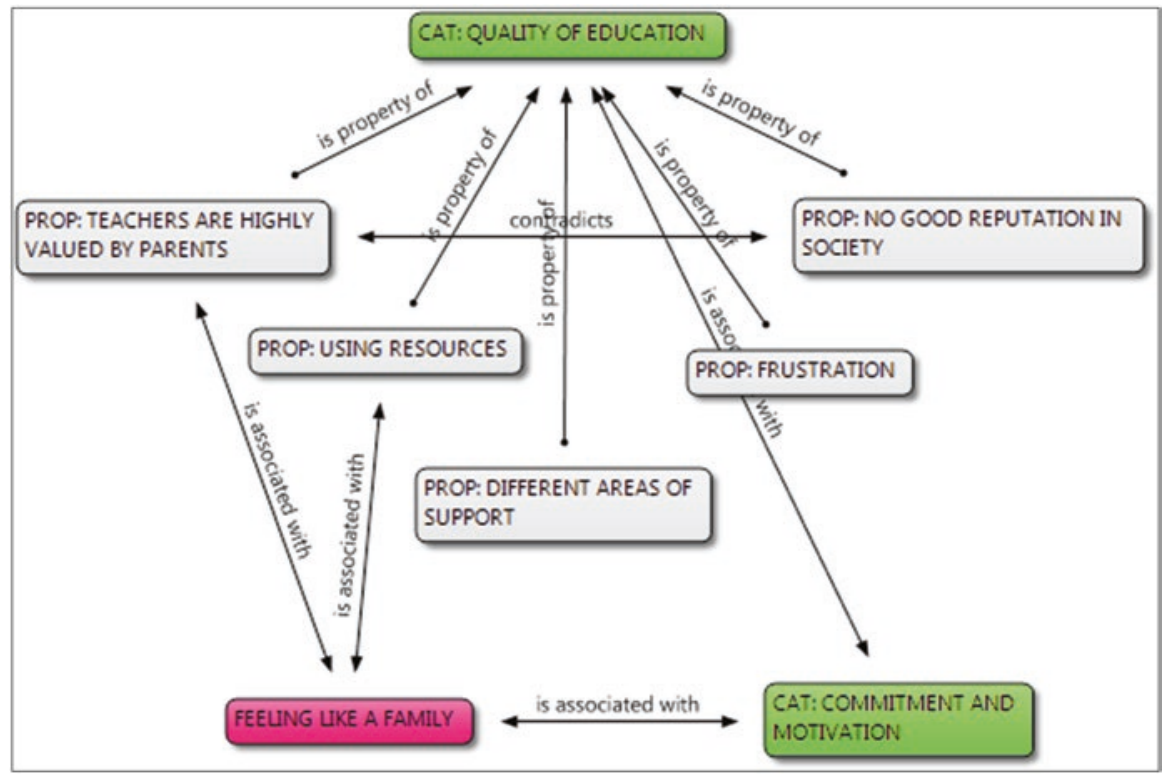

Network View 5.8 Properties of quality of education 
It seemed that the high value that parents usually attributed to the teachers did not give them enough motivation. The low reputation in society rather added to feelings of frustration and low motivation. However, also referring to the previous chapter on establishing relationships, it can be stated that the communication with parents had an important influence on the quality of education. At this point, the item "feeling like a family" comes into play. The analysis showed that the commitment of the teachers was higher when a familial atmosphere existed between teachers and parents. A high degree of commitment enhances the quality of education, as can also be seen in the next chapter.

\title{
Commitment and Motivation: Being on the Road
}

This category is based on teachers' well-being in the school community (including teaching staff, children and parents). Working with and supporting children with disabilities requires commitment and motivation. Hence, "being on the road" refers to the teachers' situation in the process of supporting children with disabilities in receiving education. The more teachers like their working environment, the more commitment and motivation can be identified. Additionally, it is essential what teachers think about their profession, that is, if it makes sense for them and what they gain from it themselves (reassurance, satisfaction or frustration, excessive demand, etc.). In this way, it is linked closely to the category quality of education. However, it differs from the latter regarding the surrounding that is involved. Quality of education refers more to teachers' macro-systems (teacher education in general, different resources and society), whereas commitment and motivation refer to the teachers' micro-systems inside school (Bronfenbrenner 1980).

\begin{abstract}
You would be happy if you see the changes of these children. One boy came to this school almost a month ago. He couldn't even walk; they brought him to our school carrying him on their back. Within one month he started to walk carrying his own bag. When we see this kind of improvement, we feel very happy for ourselves. We thank also our Almighty God. Once I convinced myself this is my profession, I like it. Especially I am observing improvements on the children. This makes me happy. I will not be offended by people's misconduct. But the profession needs commitment. The education itself brings behavioural change. That is to say it also changes your behaviour. (Abkale, teacher)
\end{abstract}

Many of the issues and actions which the teachers talked about were related to commitment. In this context, commitment can be identified as becoming active to support the child, using own resources, showing empathy for the child and caring for the child. Furthermore, the teachers talked about the goals that they wanted to reach by supporting the parents and children. Hence, they took on responsibility for educating and supporting the children. This also became visible in the teachers' knowledge about the needs of the children, including health issues. Last but not least, the degree of satisfaction with their profession had an influence on the teachers' commitment. Within the category commitment and motivation, I found out that in relation to children, commitment was shown more in cases where the teacher felt 
like family concerning the child. "I have little brothers, and I consider my students as if they are my children or my little brothers. Unless I consider them as my own family there is no way of improving their character. Thus, this needs commitment" (Kadhi, teacher). Considering students as family also means taking on responsibility for their education and issues beyond education. Hence, the teachers partly took on the responsibilities of the parents. This goes along with the aspect of 'taking on responsibility' of the category establishing relationships. Consequently, the aspect of family was a key element for improving the student's achievements and well-being.

The biggest challenge regarding the teachers in this context were motivational issues. Motivational issues include a set of feelings and circumstances that were expressed by the teachers. They reached from "not wanting to become a teacher" in the first place to lack of material and teacher training amongst others.

Hence, factors that discouraged the teachers in schools in general were the low payment and the low reputation which the job has in society. Most teachers - especially in governmental schools - seem to be frustrated or feel a lack of support in their efforts to find solutions to their problems. "You know, many teachers are quitting the job. Others go home as soon as they have finished teaching. No one wants to spend more time at school" (Biniyam, teacher). However, there were teachers who still had goals and visions for the children. Furthermore, I identified differences in teacher motivation and attitudes between schools with special settings and integrative settings in governmental schools on the other hand. This is not surprising, as special units and special schools tend to organise themselves in different ways. As the focus in these settings lies on disability, almost everybody in the special unit or school is informed about and also experienced in the challenges teachers and children with disability are facing. This means that a higher level of awareness prevails.

In addition to that, I observed a high teacher turnover in governmental schools. The same did not seem to happen as frequently in special units or special schools. This also suggests a stronger bond between the teachers in the special settings. Hence, their identification with the job was higher and their commitment led to more motivation in the job. This might also result from a feeling of community and belonging in the special settings. This sense of community might have been missing for some of the teachers of our sample especially in governmental schools and therefore have added to frustration and dissatisfaction. For teachers in special settings, the sense of belonging seemed to exist to a very high extent. This could be identified by statements like: "We feel like a family here."

In regular classrooms in governmental schools, the teachers did not seem to have many possibilities of exchange or discussion about disability issues in relation with education. An interesting aspect in this context was that many of the teachers in special units that were integrated in regular schools did not feel supported by their colleagues from the regular classrooms.

Yes, all the teachers should take training. They [regular teachers] consider everything as our [teachers in special unit] own job. They do not give any attention at all. Even if disabled children disturb in the other sections, they order us to come and take them. They don't even 
think of helping us with their potential. Last time one boy was missing and we were worried too much, finally he was found. The boy was autistic; even if seeing him they don't bother about him. Even if we go to our home, they phone us if there is any problem. (Abkale, teacher)

This indicates that the separation of the classes separates the teachers in this system. This again leads to a lack of cooperation between the teachers. Therefore solidarity or good working climate through exchange and mutual understanding were major factors for teacher motivation when having to deal with special needs and inclusion. These situations might also lead to a positive feeling of community or a familial atmosphere in the school.

The teachers in the special settings mostly received better training than regular teachers. This was due to the fact that those teachers were usually special needs teachers from teacher training institutions that had a focus on special needs. Nevertheless, special needs teachers also claimed that they needed more training, tools, etc. for teaching children with special needs.

I observed that the conditions for children with disabilities in special settings seemed to be better in relation to the teachers' knowledge and training as regards class management, disability issues in general and teaching methods. As disability was an everyday reality for those teachers, their level of awareness and engagement was usually higher. The colleagues and the school administration in special schools seemed to be much more involved also in disability-specific topics, which contributed to a positive attitude concerning the inclusion of children with disabilities. This was an important aspect for teacher motivation.

Looking back on the discussion, a first reasoning would be that a feeling of togetherness and belonging becomes crucial for teacher motivation. Referring to the different settings of the sample, the positive climate, teacher motivation, commitment and the "feeling of being a family", a kind of "community feeling", dominated in the special settings. This might also be related to the size of the schools and classrooms in those settings.

This community feeling seemed to increase the teachers' mutual respect, their feeling of responsibility and belonging to the school. Hence, approaching school itself as a community can be very fruitful especially regarding the Ethiopian context. The special societal and cultural meaning of community in Ethiopia (Schiemer 2013) seems to have an essential impact on teachers' commitment and motivation. The following network view lists the properties of the category commitment and motivation.

Almost all of the teachers were aware of the problems and challenges that people and especially children with disabilities faced. The tendency showed that the teachers in special units were more committed to addressing these problems than the teachers in integrative settings, who seemed to be detached and more frustrated.

What is described here points at conditions for the teachers' commitment and motivation. In other words, with a lack of certain circumstances, the teachers lost or did not develop commitment in their profession. Teaching in an environment where support, solidarity and a familial atmosphere did not exist, teacher motivation was more likely to turn into frustration. However, there were teachers who were very committed to their profession. 


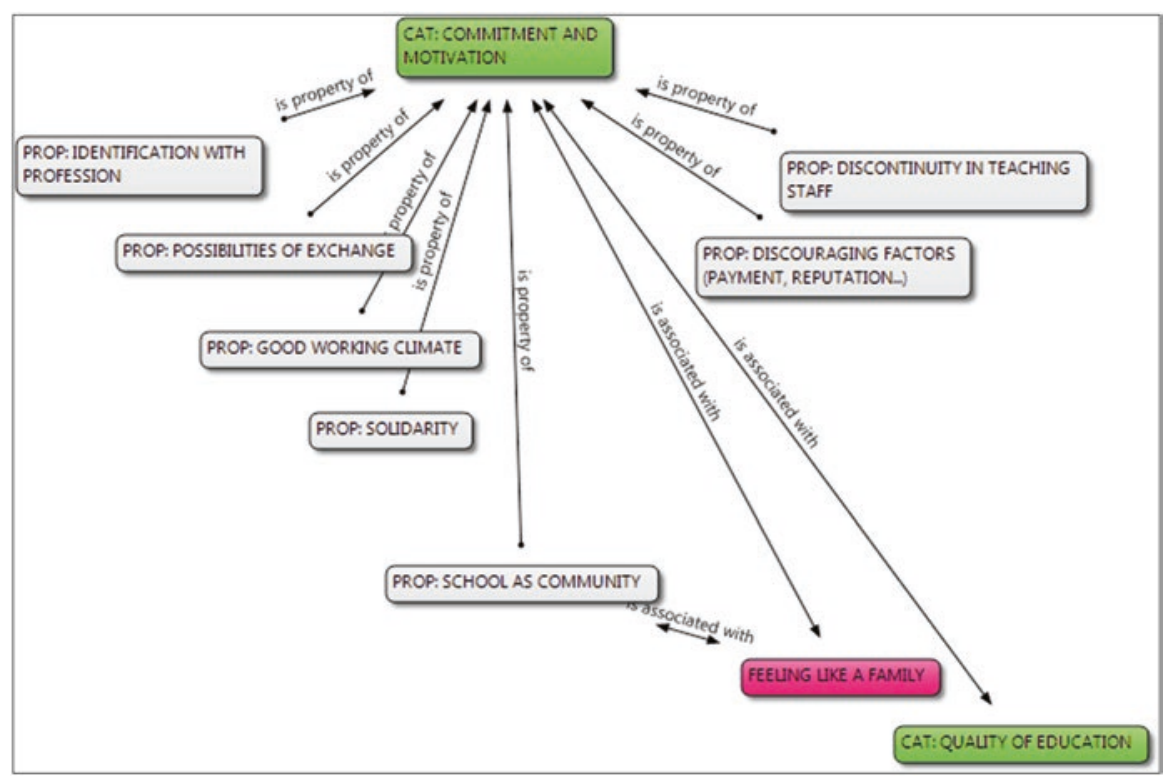

Network View 5.9 Properties of commitment and motivation

M Why did you want to teach these children? What is the reason?

A The reason?

Y Yes.

A Shall I tell you the real reason? Well, that is because of an internal yearning. While I was teaching regular students, special needs students would come to the school. Since neither the teachers nor the administration have any idea about special needs, they would be told to go back home. Then, I began to think. I said to myself, 'What would I do if these are my children since I myself have children'. I would think about this the whole night. There were one beautiful girl and two boys. They were deaf. They were in my friend's class. Their parents were called and were told to take back their children. They did that with tears. Three days later, a girl with behaviour disorder was dismissed. Then, while sleeping at night, I began to think of something. I said to myself, 'Why shouldn't I take these students to my class, sit them in the front row and control them?' I then started with two of my students and these students. I desired to see change in them. I didn't know sign language. There was also a blind student. They were altogether five disabled students. I sat them in the front seats. I would write for them. I began to teach them in this way. (Adanesh, teacher)

\section{Summary and the Meaning of Education for Teachers}

The main aspect that was part of all categories that developed from the teachers' interviews was taking on responsibility. This was also the main aspect in the parents' interviews. Establishing relationships, quality of education and commitment and motivation are categories that are mainly related to the interaction between parents, children and teachers and the responsibilities that were shared, distributed 
or included in this interaction. Furthermore, all of the categories are connected to the quality of the educational environment for children with disabilities. Hence, they have an influence on the quality of education. Even though the children were not given much emphasis in this part, the teachers were aware of their challenges.

The other thing is that it is difficult to teach both disabled students and normal students together. Especially for the teachers it is difficult to manage. For instance, those who are mentally retarded cannot cope with other students. It is difficult to teach them equally. The way they understand the lesson is different. The normal students can understand quickly, whereas the mentally retarded children need quite a long time to understand. Those disabled children who have got a problem physically, since they don't have mental problems, can understand any subject like normal students. But, there is a problem when they do sport activities. It is not possible to train them in a comfortable manner. (Kadhi, teacher)

It became evident that it was almost impossible to focus on an individual child due to the high number of children and the workload that the teachers faced. In other words, if they were given the required support, they would not have a feeling of being overburdened. Nevertheless, it was clear to the teachers how important education for children with disabilities is. Hence, also here the aspect of responsibility got special attention. Teachers who took on responsibility for the children that they were teaching showed a high level of commitment but at the same time seemed to be more exposed to potential frustration. They reached their limits more often, as their striving to support the children often went beyond their possibilities. Therefore, teachers who did not take on so much responsibility, who did not show as much commitment to quality of education for all children as other teachers, were not exposed to this kind of problems. However, the teachers' possibilities were very important in this context. They depended on their personal skills, their education and their experience. Sometimes a lack of interest also led to lower quality in the teaching-learning process. This lack of interest and low motivation usually resulted from limiting factors (lack of material, lack of teacher training, etc.). Finally, even though the tendency was such that in special settings the teachers were more able to support the children, in school E the teachers seemed to be very well trained and supported in managing the integrative setting there.

They are lucky when they come to this school. When they leave the school completing grade eight after national examination, they will face problems when they go to government schools. They do not support them like us; they do not protect them. As you see here the compound is small, we do have only fifty students in a class; because of this they are privileged. In school E I do not think they have problems. (Aster, teacher)

This teacher emphasised the problematic situation in governmental schools compared to school E where he was working. Hence, it is clear that the quality of education that the children received differed from school to school. This fact is also addressed in the OECD report "Equity and Equality in Education" (OECD 2012). "Low performing disadvantaged schools often lack the internal capacity or support to improve, as school leaders and teachers and the environments of schools, classrooms and neighbourhoods frequently fail to offer a quality learning experience for the most disadvantaged" (OECD 2012, 4). 


\section{Defining Conflicts and Relating Categories}

This part of the book is about developing theoretical concepts that explain the relations between the categories that were discussed above.

The following table gives an overview of the categories. The core category (feeling like a family) is left aside as it will be considered on a different level of the analysis.

In each of the groups (children, parents, teachers), there seems to be a category that marks a starting point (necessary basis, developing trust, investing in working atmosphere) and a stage of dispute (struggle, breaking free, needing support). Furthermore, it stands out that only in regard to parents and teachers, categories have developed which reach the phase of the already discussed "atmosphere of departure" (breaking free, departure, being on the road). It cannot be neglected that also in the children's interviews clear goals were set and ways towards reaching these goals were defined. Hence, also for children, education means an opening door for their future. In the words of the capability approach, the children's capability of "education" can lead to the functioning of "developing a sense of belonging" (to society). To be more specific, the functioning is precisely the reality of belonging to society by being a valued member (doing valuable acts).

Yet, it is also evident that children are still in the midst of the struggle of where they belong. Regarding the parents, the walk of shame is a category that clearly illustrates the parents' struggle towards a change in attitude. As far as the teachers are concerned, the struggle that could be identified takes place in the areas of commitment and motivation, support and teacher education, possibilities and frustration. This can be subsumed under taking on responsibility for the children and education.

Hence, one consequence of education for children with disabilities is a struggle about belongingness. Thereby, the disability and consequently exclusion and restrictions form the basis. For parents a struggle of changing their attitude is the main conflict. The situation of sometimes being perceived in their communities as cursed by being parents of children with disabilities and also their own attitudes form the starting point of their conflict. As far as the teachers are concerned, a struggle of taking on responsibility in their profession receives the most attention. Regarding this conflict, the low reputation of their profession in society can be seen as one indicator. However, different interests (e.g. wanting to change professions) also

Table 5.1 Overview of categories

\begin{tabular}{l|l|l}
\hline Children & Parents & Teachers \\
\hline $\begin{array}{l}\text { Developing a positive } \\
\text { self-concept (necessary } \\
\text { basis) }\end{array}$ & $\begin{array}{l}\text { Establishing knowledge about the } \\
\text { child and education (developing } \\
\text { trust) }\end{array}$ & $\begin{array}{l}\text { Establishing relationships } \\
\text { (investing in working } \\
\text { atmosphere) }\end{array}$ \\
\hline $\begin{array}{l}\text { Question of belonging } \\
\text { (struggle) }\end{array}$ & $\begin{array}{l}\text { "The walk of shame" (breaking } \\
\text { free) }\end{array}$ & $\begin{array}{l}\text { Quality of education (needing } \\
\text { support) }\end{array}$ \\
\hline & Parental support (departure) & $\begin{array}{l}\text { Commitment and motivation } \\
\text { (being on the road) }\end{array}$ \\
\hline
\end{tabular}




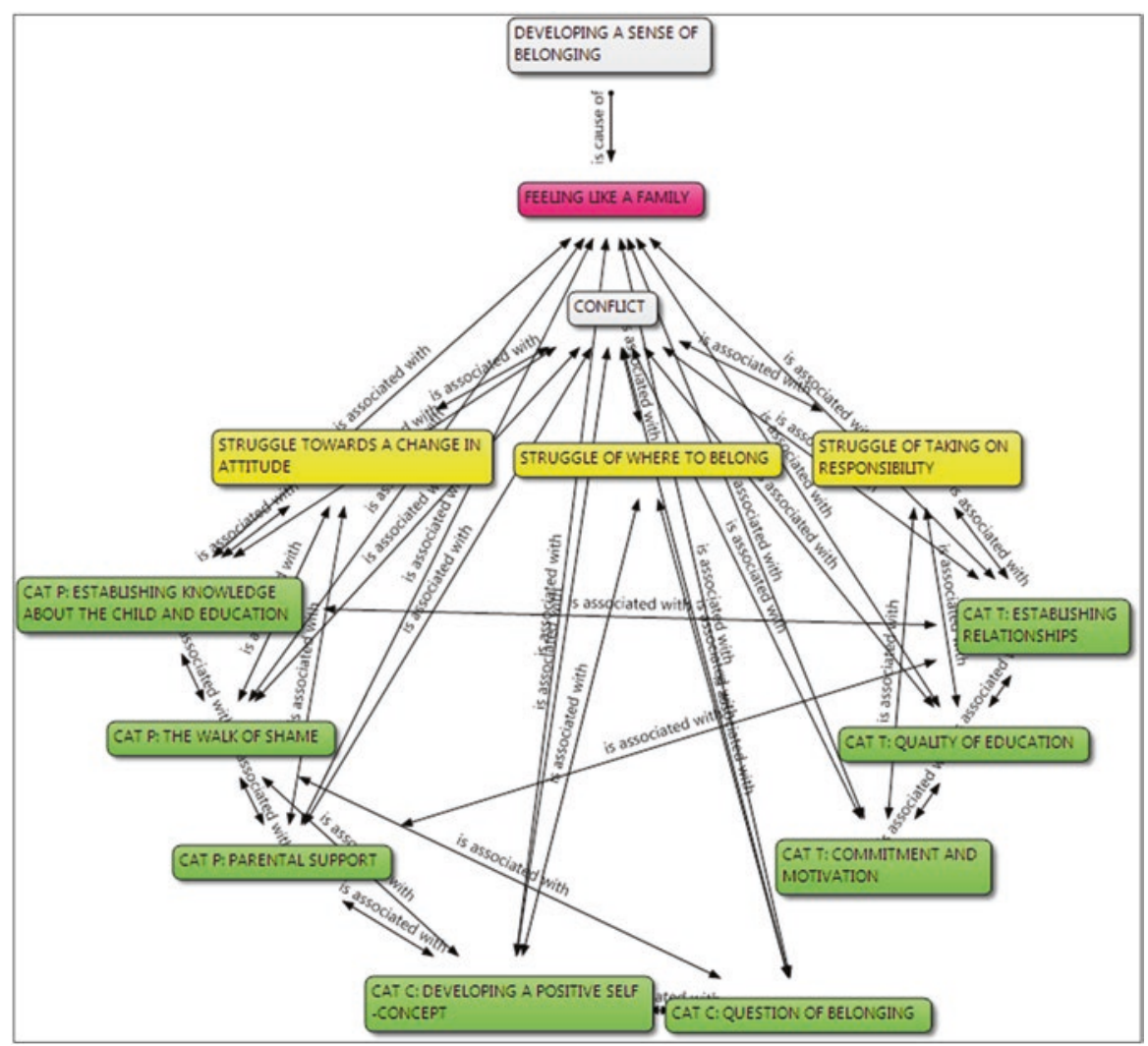

Network View 5.10 Conflicts related to categories

come into play. It becomes clear that conflicts do exist for all participants. These conflicts hamper the capability for education in order to reach the functioning of belonging in the children. Feeling like a family is the main vector to pull the conflicts towards solutions.

The following network view illustrates the conflicts and relations between the categories, including the core category feeling like a family.

The core category feeling like a family constitutes a concept for managing difficult situations as it solves the identified conflicts on a certain level by leading towards "developing a sense of belonging". Looking at "developing a sense of belonging" as a functioning that develops through certain capabilities, one barrier, but also motor, to develop such functionings is - next to feeling like a family - poverty, as will be explained at the end of this chapter. However, it must be pointed out that the core category can also be identified as a functioning on a different level (e.g. when looking at it on the meso-level, where only the school community is contemplated, not society in general). 
For children one major reason for striving to reach their goals of being educated and independent is being able to support the family. This supports developing $a$ positive self-concept. By reaching this point, they would integrate themselves in society and define their place of belonging, hence answering the question of belonging. For parents, having a child with a disability puts them in the situation of being special and excluded in a certain way. Establishing knowledge about the child and education together with walking the walk of shame changes their attitudes and opens up the possibility to belong to the school community, which in some cases gives them a feeling of family and hence also a sense of belonging. Those who do not exhibit such a feeling do not develop a sense of belonging in the same way to school, which influences parental involvement and in consequence parental support for children with disabilities. Teachers treating children as well as parents "like family" members have a different approach towards their profession and their responsibility. Hence, feeling like a family seems to strengthen the people who share this feeling. However, the children depend on the parents' change in attitudes and teachers' taking on responsibilities to reach their goals (and functionings). By supporting the child in the mentioned ways, parents and teachers provide the necessary environment for children with disabilities to develop a positive self-concept and furthermore a sense of belonging. This means that the core category feeling like a family related to teachers and parents finally supports the children in reaching their goals. Hence, the school environment regarding relations and attitudes is prepared for the child to depart towards a valued, equal, accepted and respected life. The "only" aspect left open is the society, who has to accept and realise that people with disabilities can be of value for society like any other member.

Parents and teachers benefit already in the environment of the school, as feeling like a family is there to support them. They gain their values of respect and acceptance already at that point. For children, it is different as they gain positive energy from their access to school, but their goal to support their family and be of value to the society also by other means can only come into effect in the future. Feeling like a family related to children (e.g. being able to support the family) therefore constitutes only a possibility without guarantee. However, what can already happen at this point is the development of a positive self-concept.

On the other hand, parents who cannot be related to the core category still struggle with certain aspects of the situation of their child being at school. Here, it cannot be forgotten that poverty plays a major role. If it is poverty that prevents parents from going to schools and develop a closer relationship with teachers and invest time in getting involved, it can be identified as a major barrier to "developing a sense of belonging". Teachers who do not have a close relationship with parents (establishing relationships) and/or children usually seem to exhibit less commitment (commitment and motivation) and show less satisfaction regarding their profession. This has consequences for the quality of education for children with disabilities (as well as for children without disabilities). 


\section{Listening to Other Experts}

Most $^{23}$ of the experts were interviewed following theoretical sampling strategies. This means that emerging topics and categories were further elaborated. In other words, in this chapter, the categories and topics are confirmed and enriched by including the experts' perspective. ${ }^{24}$ Furthermore it adds supplementary information and important issues that were not given attention before. I collected the data (experts from inside and outside the schools) in addition to the cases (children, parents, teachers). During the analysis of these interviews, the category atmosphere of departure (positive developments) developed from the discussion that will be elaborated in the following.

The atmosphere of departure describes a development towards a change in attitude in society regarding people with disabilities. This change is supported by certain developments but also hampered by some aspects. Experts generally have the impression that positive developments regarding attitudes towards persons with disabilities can be observed in the Ethiopian society.

After analysing the children's, teachers' and parents' interviews, the analysis of the experts' interviews provided me with a fourth perspective on education for children with disabilities. In these interviews, different problems were identified as number one problem concerning education for children with disabilities. The most prominent one was attitudes. Furthermore, the aspects of religion and belief, which were regarded as a major factor influencing attitudes, were examined referring to a representative of the Orthodox $\mathrm{Church}^{25}$ and its doctrines. Another point that was discussed in the experts' interviews was the aspect of community. It was referred to either as the source of negative attitudes towards disability or as a supporting entity for families who had children with disabilities. Not surprisingly, emphasis was also put on teacher education. In this respect, the issue of commitment was raised on several occasions. The aspect of parental involvement also got special attention in some of the interviews. Last but not least, the implementation of legislation was discussed from the experts' perspectives.

\footnotetext{
${ }^{23}$ Some of the experts were also interviewed at the beginning of the research phase, where theoretical sampling was not applied. These interviews gave an overview of the situation for children with disabilities and were more open than interviews with experts at a later stage, which were geared to previously collected data.

${ }^{24}$ The whole second and third phases of the field research were also dedicated to enriching and supporting previously developed preliminary categories.

${ }^{25}$ As already mentioned, it was not possible to contact representatives from the Muslim mosque. Hence, this perspective could only be derived from the interview with a representative from the Orthodox Church.
} 


\section{Attitudes and Awareness}

This chapter complements in particular the parents' category the walk of shame. However, not only the parents were addressed here. Therefore, new elements were discussed that are related to this category.

The attitudinal problem was raised as problem number one by the Finnish expert in the ministry, by the special needs expert Yeshitla Mulat ${ }^{26}$ and by the programme officers of LIGHT FOR THE WORLD. "[...] when it comes to the disability issue, when it comes to the inclusion issue, when it comes to the mainstreaming of, you know, disability and social services and development services, there is a real lack of awareness of the topic as well from the top officials down to the low level institutions" (Abraham, LIGHT FOR THE WORLD). At the same time, the experts observed changes in attitudes. "I can clearly, clearly, clearly see that attitudes are changing and ah, this inclusive education approach is also sort of taking place among professionals" (Finnish special needs expert in the Ministry of Education). It seems that also here an atmosphere of departure amongst higher levels prevails. This atmosphere was already observed in the parents' category the walk of shame. There, it was related to the hopes that the parents developed as soon as their child attended a school. However, in this case "departure" refers to the change of general attitudes towards disability in society. Both can be related, as on the one hand schools - as public institutions - are more likely to start to accept children with disabilities through a societal change of attitudes and, on the other hand, parents are also a part of society and their change of attitudes also influences society. Jana Zehle, at that time special needs expert at Addis Ababa University (AAU), comes to the same conclusion regarding the parents. Even though the parents were sometimes not aware that their child with a disability could attend a school or they were afraid of being discriminated, a clear change in attitudes and awareness could be observed in Addis Ababa. Uncertainty sometimes still emerges when parents and children are confronted with unexpected barriers: "I think it starts with the attitude, [...] but when the parents are convinced [...] and they or the child are confronted with barriers, a relapse [in attitudes] can easily happen" (Jana Zehle, AAU). All in all, the experts observed a development in Addis Ababa where not only parents of children with disabilities seem to be more interested in education in general.

An atmosphere of departure regarding education was also suggested by the vast construction of new school buildings all over the country. However, a lack of awareness seemed to cumber accessibility for children with disabilities. "The schools, all the schools that have been constructed in Ethiopia, could have been made accessible. Especially the ones that have been constructed recently over the past five/six years could have been made accessible [...]" (Abraham, LIGHT FOR THE

\footnotetext{
26 "I have been working in the Ministry of Education, and I have been the head of the teacher education programme, and I was facilitating, at a federal level, the education programme, the general education programme, including the special needs education at a federal level to be delivered in schools, as well as the special teacher training in the universities and colleges" (Yeshitla Mulat, special needs expert).
} 
WORLD). All new schools were built according to the same scheme. They were five floors high, with stairs that the children had to climb. Hence, especially for children with physical disabilities, it might be a problem to reach their classrooms. Changes of attitudes seem to have taken place to some extent in society.

Now there is a positive attitude and work by the society and the government. Let's take leprosy. In the old days, it was considered as contagious, it transmitted from one person to another and they were stigmatized, now due to media awareness they aren't considered as before, that it came by the curse of parents. Generally we are changing our old attitude towards disabled people. (Geta, expert and teacher)

The experts also believed that the teachers' awareness of disabilities in general was good. This change in attitude can partly be explained by the environment, as one expert described. He also used examples of leprosy, amputation because of mines, former combatants who were injured be the Derg ${ }^{27}$ regime (Melese, expert and teacher). Hence, the visibility of people with disabilities who were obviously injured seemed to influence many people's attitudes towards disability.

The higher awareness and positive attitude resulted in teachers and other people taking more initiatives. These initiatives to raise awareness in the schools, and the use of different media, led to a change in attitudes. Principals spoke about different programmes that they were implementing in an effort to raise awareness. Amongst them were sign language training for hearing students as well as for parents, measures to raise awareness during the morning ceremonies, using mini-media, ${ }^{28}$ etc. It became clear that children were perceived to be the best multipliers for distributing information on disability-related topics to the families and communities.

[The disability clubs in the schools, including teachers and students] are the ones to regularly on daily basis from Monday to Friday raise awareness through different mechanisms [mini-media] yes they use mini-media, school mini-media. Through poems, through drama all different... they really teach the whole school community, teachers and students on daily basis and the... they are, you know the children they are really the means and the tools who are now talking and teaching to their parents, to their neighbours, to their family members, to the relatives, who are really changing the awareness level and the attitudes of the people at this moment. (Getachew, LIGHT FOR THE WORLD)

What can be observed in this case is that children are also seen as capable of taking on responsibility for the task of changing attitudes in the communities. In regard to the community as such, most of the experts felt a change in attitudes. The Minister of Education came to the conclusion that the communities around the schools had a major influence on the schools: "So more or less the schools are led [...] by the community. This is our achievement" (Demeke Mekonnen, Minister of Education). He pointed out that the surrounding communities were highly involved and participated in discussions with the school board. This might also be related to a changing attitude towards education. The Minister of Education sees the Ethiopian society trans-

\footnotetext{
${ }^{27}$ See Chap. 2 "Understanding the context..."

${ }^{28}$ Mini-media is a kind of radio station in the schools that is used by children and teachers to distribute all kinds of information.
} 
form into a knowledge-based society. This statement underscores the importance of knowledge. The aspects mentioned here are not so much related to disability directly as to education in general. The representative of the Orthodox Church, for example, was convinced that the Ethiopian people had changed their attitudes towards disability in general. "Another example, my teacher was blind; we went to different places by mini-bus. When we entered in the mini-bus, everybody would rise up. This is because the attitude of the people towards disability has changed. Therefore, they treat them; they also contribute money" (Administrative Head of the Ethiopian Orthodox Tewahedo Church). What can be observed in this context is that a charity model of disability often prevails in the society. The change in attitudes seemed to take place above all in terms of refraining from the convictions that people with disabilities were cursed (e.g. Geta, expert and teacher). Another important aspect regarding the change in attitudes involves community-based rehabilitation workers (CBR workers). As CBR workers work at the grass root level, they reach the people in the communities and at home. In this way, it is possible to raise awareness within the communities, to support parents by accompanying them to school for a first interview, etc. (Jana Zehle, AAU). The experts thus identified different ways of creating awareness and changing attitudes regarding people with disabilities at different levels of the Ethiopian society. Yet, attitudes are influenced to a great extent by the people's beliefs and religion.

\section{Religion}

This chapter explores aspects that can be related to the parents' walk of shame. The parents referred a lot to their belief and to God in general during the interviews. However, it seemed that there were differences between what people believed and what the Church wanted to communicate, especially regarding disability.

At one time God teaches his disciples that a lame person was cured. At that time people
asked Jesus Christ, why was he born handicapped? Was it because of his sins, his mother's
sins, or his family's sins that he became handicapped? Jesus Christ answered it was not
because of his sins or his family's sins; it was because God wanted to show a miracle to the
world. (Administrative Head of the Ethiopian Orthodox Tewahedo Church)

Hence, there are clear misunderstandings between what the Church teaches and what people think about the role of God. The expert interview showed that the text in the Bible could be interpreted in different ways. According to the interviewee, one miracle is Christ's resurrection. Another point referred to God's wisdom and knowledge. He wanted people to learn from each other. The argument in this aspect was that people could not learn from each other if they were all the same.

Therefore, since there are rich people, there will be poor people. If there are normal people, there will be disabled people. If there are evil people, there will be children of God. If there are happy people, there will be sad people. If there is light, there will be dark. If there are kind people, there will be mean people. In order to show God's wisdom, there are children 
who are born normal, and there are children who are born with disabilities. (Administrative Head of the Ethiopian Orthodox Tewahedo Church)

It was clearly stated that the Church does not believe that disability comes from sin. Additionally, in this case, the Church employed people with disabilities and in this way integrated them in their institution. Furthermore, according to the interviewee, the Church teaches not to discriminate people with disabilities. Accordingly, there is a clear gap between people's beliefs and what the Church teaches. "If disabled people are rehabilitated and supported, they can actively work like normal people. As a human being: rich, poor; black, white; normal, disabled; before God everybody is equal. This is what the Church preaches" (Administrative Head of the Ethiopian Orthodox Tewahedo Church). The question if God cursed people who might have done something wrong, and if disability could be seen as a punishment for that, was answered negatively in the first quotation. Nevertheless, this belief is widespread. The majority of the people who were interviewed were very religious. Their belief influenced their everyday life to a great extent. Consequently, the importance of the Church and respect for the Almighty God could be observed in many of the interviews. Even though the Orthodox Church seemed not to disseminate the belief in disability as a curse, it remained in the heads of its followers. Traditional beliefs could play a role here too.

\section{Teacher Training}

Demeke Mekonnen, the Ethiopian Minister of Education, identified quality assurance as the number one challenge regarding education in Ethiopia. In this respect, good teacher education was essential for quality in education. Teachers had to be equipped with tools in order to be able to manage their classrooms in a way that ensured the greatest possible benefit for the children. Regarding inclusive education, this point has to get even more attention, as the teacher is confronted with even more diversity ${ }^{29}$ of special needs that the children in his/her classroom exhibit. Hence, quality teacher education is indispensable for making inclusive classrooms possible. This chapter therefore supports the category quality of education.

Ma: What are the three major changes you think that have to take place in the very near future to make inclusive education a reality?

SF: In the near future [...] well I would say, that teacher training, teacher training and teacher training $[\ldots]$ yeah, when teachers they have to be trained I mean properly to manage inclusive classrooms. (Finnish special needs expert at the Ministry of Education)

However, most of the teachers could not be made responsible for not knowing how to manage an inclusive classroom. Yetnebersh Nigussie from ECDD (Ethiopian

\footnotetext{
${ }^{29}$ The researcher believes that diversity and special needs can also be found in regular classrooms without children with disabilities.
} 
Centre for Disability and Development) stated that it was the lack of experience rather than the lack of commitment on the teachers' part. She saw a clear need to support teachers at the classroom level. Consequently, the focus should be put on practical skills. In this context, Jana Zehle identified a problem in teacher training regarding the intensity of the mandatory special needs course which could already be observed in the teachers' interviews. She claimed that this course provided the teachers with insights into the topic of disability but did not seem to equip them properly with tools for handling an inclusive classroom. Furthermore, she observed differences in the quality of integration (as it was not yet real inclusion) in different schools that might be due to a higher or lower degree of engagement of the teachers. Hence, teachers' engagement once more becomes a major aspect of functioning inclusion. However, Jana Zehle (AAU) stated that very often it was not easy to keep the enthusiasm of some teachers as they were often overburdened or lost motivation because of a lack of material, lack of special teacher education, and general lack of support, etc.

Another aspect that seemed to be a challenge for teachers according to Yeshitla Mulat was the fact that they were evaluated according to how far they had proceeded with their textbooks during the school year. The inclusion of children with disabilities might slow down the completion of the textbook, as teachers did not know about teaching methods that supported all students similarly according to their needs. Therefore, children with disabilities were usually treated differently from the rest of the class, which took more time and might be of less quality. This might be the case because the teachers did not have enough time and maybe energy in classrooms of 60 children. As the teachers were also not equipped with the practical skills to handle these challenges, they faced severe problems (Yeshitla Mulat, special needs expert). Teachers' preparedness will be addressed again at a later point. It is also rated as more important than the availability of material when it comes to inclusion. In this context, one problematic aspect that was raised especially by school principals was the scarcity of trained staff. However, the schools had started to be equipped with one special needs expert. These experts support teachers and students.

My task is to teach how to handle disabled students. I also teach students study skills. I instruct people about the best sitting arrangement in the classroom. I see to it that teachers do not write in very small characters on the board. I also inform them that they should not be too fast when they teach the students. (Melese, expert and teacher)

It became clear that already this kind of advice might be of major importance for teachers and consequently for children with disabilities. It is the first step towards identifying the needs of the children and reacting to them.

Not surprisingly, the experts defined a clear need for teacher training. Practical skills for classroom management were needed most. As could be demonstrated, the statements of the experts corresponded with the outcomes of the analysis and hence supported and enriched the relevant categories. Teacher training cannot lead to quality education without teachers' commitment. The next chapter focuses on this aspect. 


\section{Teachers' Commitment}

This chapter supports the category commitment and motivation. The impression of some experts was that teachers did not like to spend more time at school than necessary. Hence, sometimes negative perceptions of teachers' commitment and their willingness to invest resources prevailed (e.g. Melses, expert and teacher). However, there were many principals and other experts who praised teachers' dedication to their profession. In some schools, teachers even supported children with disabilities beyond issues of education (e.g. financially) (see, e.g. Geta, expert and teacher; Melese, expert and teacher). Other experts spoke about the teachers' creativity, which was often used to create teaching material with things that were available to them (Jana Zehle, AAU). Hence, from the experts' perspectives, there were teachers who showed a lot of commitment and engagement. Still there was a need for even more commitment: "I mean, we do have to do more and commit ourselves more with further strength and awareness and knowledge, as to what we are expected to do, what we are supposed to do" (Temesgen, expert and teacher).

\section{Parental Involvement}

In this chapter, the category parental support will be enriched. The experts also mentioned that it was the parents' energy or time that was not available for them to support their children at school. In this context, poor families were mentioned explicitly (Jana Zehle, AAU; Melese, expert and teacher). In other words, poor families had less time for supporting their children at school, as they had to ensure their daily income. One expert made a clear distinction between two categories of parents:

I have already said that there are two categories of parents. Educated parents come to inquire about their children. They want to know how their child is doing. We tell them. Uneducated, poor parents don't mind so much. They don't even come when we call them. Only 10 or 15 out of 60 such parents come. When they are asked why they failed to come, they give many excuses. They give priority to social commitment. They only come when we celebrate holidays, which makes them happy. They even help us a lot then. Educated parents buy the artifacts produced by their children. Hence, they cooperate in this way. (Bruck, expert and teacher)

From the experts' perspective, this statement underscores the perception of a clear difference between poor families and families that were well-off. To them, poverty and not being educated were related in this way. In other words, poor parents were usually more likely to be illiterate and consequently also less involved in school-related aspects. Accordingly, the aspect of poverty played a major role regarding parental involvement. Furthermore, parental involvement was often related to the frequency with which parents came and asked about their children or how often they could come when they were called by the teachers. In general, the experts, who demonstrated awareness of the parents' problems, had the explana- 
tions for a lower degree of parental involvement. They knew about time restrictions and problems of generating income.

The big problem is poverty. Since most of them are daily labourers, they are unable to come. There are also many parents who can't come because of transportation problems. There are some families who bring their children here and stay the whole day in the school because they don't have money for transportation. These kinds of problems force them not to come. (Bruck, expert and teacher)

This shows the influence that poverty can have on the children's education regarding parental involvement. Consequently, it might also influence the children's self-perception, as less involvement also means less support.

\section{Implementation of Legislation}

One of the main aspects that were discussed in the experts' interviews was the implementation of inclusive education. Again, the teachers' category commitment and motivation was most prominent here. The main problem that was addressed was the infeasibility of the environment for inclusive education. In this context, the already discussed lack of teacher training and lack of sufficient staff constituted the major barriers. One problem that was seen as a result of this was the teachers' loss of motivation (Geta, expert and teacher). Hence, two mutually increasing challenges can be identified at this point: on the one hand, more commitment amongst teachers is needed for inclusive education, and on the other hand, the attempt to implement inclusive education without appropriate preparation can lead to demotivation. However, there was no doubt amongst the experts that the law and regulations for implementing inclusive education existed in Ethiopia. "Drafting or enacting a law doesn't create any change unless it is properly applied, I can't judge if we applied all the laws that were made by the government. The problem arises from issues of application. Otherwise we have extraordinary laws" (Habtamu, expert and teacher). Doubts arose only related to control mechanisms. For example, who controls whether a school accepts students with disabilities and what are the consequences if it fails to do so? Principals of the schools also identified problems in this regard:

For example, there are blind students who learn here, but they don't get any support. They

don't have books. It is written that they have equal opportunities, but this is not implemented. It is easy to write it on paper, but it is difficult to put it into effect. Higher authorities do not follow up the implementation. (Adanesh, expert and teacher)

Ethiopia is not the only country where the law is in place while its implementation is lagging behind. Nevertheless, the negative effects that this has on the motivation of not only teachers but also children and parents must not be underestimated. Without the instruments (teacher training, material, information, awareness, support, etc.), it will be impossible to implement inclusive education on a broader basis. Putting motivated teachers in such a situation can have negative consequences for teacher motivation and therefore for the education of children with disabilities. 


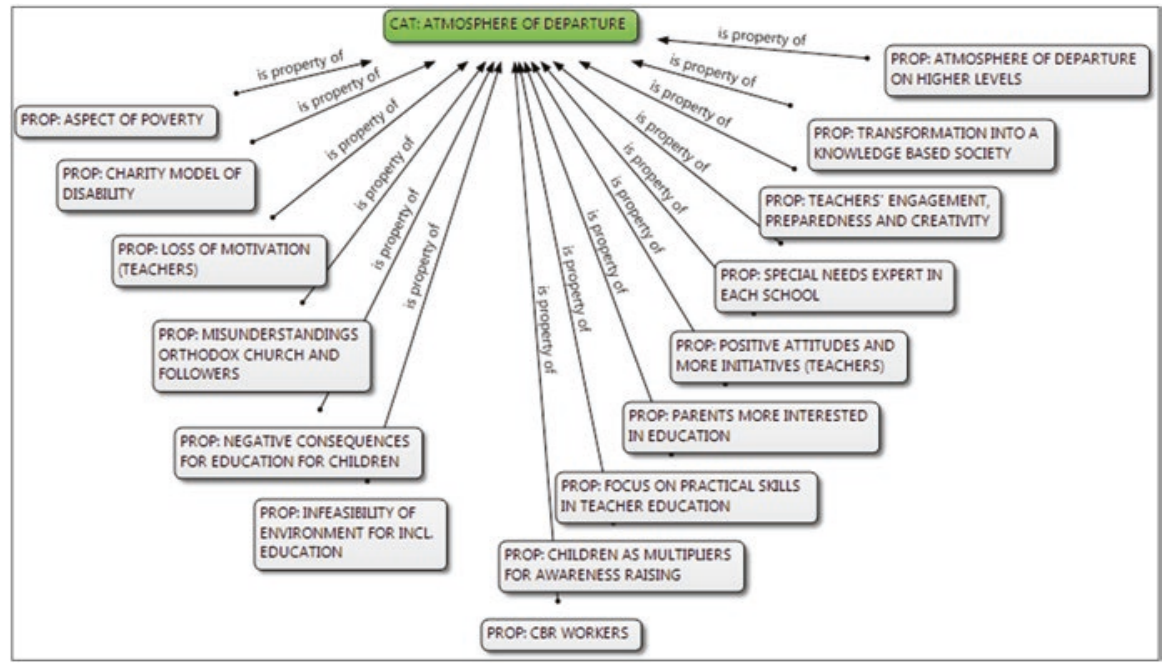

Network View 5.11 Properties of atmosphere of departure

\section{Summary}

The analysis and description of data collected from further informants led to additional aspects and enriched some of the existing categories, namely, the walk of shame, quality of education, commitment and motivation, parental support and question of belonging. ${ }^{30}$ I called the category which developed from this discussion atmosphere of departure, which will be explained below. To continue in a consistent way, the following network view shows the properties of the category.

The left-hand side of the network view contains hindering aspects of an atmosphere of departure, whereas the right-hand side lists the supporting aspects. This explains that the atmosphere of departure is also sometimes confined by various aspects. However, as the supporting aspects predominate over the hindering aspects, it becomes clear that all in all the analysis of the experts' interviews showed a positive picture regarding the change of environments (including attitudes, physical environment, relationships, etc.) for education for children with disabilities. Further thoughts on this process are presented later in the development of the theory.

\footnotetext{
${ }^{30}$ The three categories that are not mentioned here were referred to in the discussion, as most of the categories are interrelated.
} 


\section{References}

Birks, M., \& Mills, J. (2011). Grounded theory. A practical guide. Los Angeles/London/New Delhi/Singapore/Washington, DC: Sage.

Bronfenbrenner, U. (1980). The ecology of human development. Experiments by nature and design. Cambridge: Harvard University.

Charmaz, K. (2003). Qualitative interviewing and grounded theory analysis. In J. A. Holstein \& J. F. Gubrium (Eds.), Inside interviewing: New lenses, new concerns. Thousand Oaks: Sage.

Charmaz, K. (2006). Constructing grounded theory: A practical guide through qualitative analysis. London/Thousand Oaks/New Delhi: Sage.

Charmaz, K. (2009). Shifting the grounds: Constructivist grounded theory methods. In J. M. Morse (Ed.), Developing grounded theory. The second generation (pp. 127-154). Walnut Creek: Left Coast Press.

OECD. (2012). Equity and quality in education. Supporting disadvantaged students and schools. OECD.

Schiemer, M. (2013). Zur Bedeutung von Individuum und Gemeinschaft in einer fremden Kultur am Beispiel Bildung für Kinder mit Behinderung. In P. Sehrbrock, A. Erdélyi, \& S. Gand (Eds.), Internationale und vergleichende Heil- und Sonderpädagogik und Inklusion (pp. 184191). Bad Heilbrunn: Klinkhardt.

Schiemer, M., \& Proyer, M. (2013). Teaching children with disabilities: ICTs in Bangkok and Addis Ababa. Multicultural Education \& Technology Journal, 7(2/3), 99-112.

Open Access This chapter is licensed under the terms of the Creative Commons Attribution 4.0 International License (http://creativecommons.org/licenses/by/4.0/), which permits use, sharing, adaptation, distribution and reproduction in any medium or format, as long as you give appropriate credit to the original author(s) and the source, provide a link to the Creative Commons license and indicate if changes were made.

The images or other third party material in this chapter are included in the chapter's Creative Commons license, unless indicated otherwise in a credit line to the material. If material is not included in the chapter's Creative Commons license and your intended use is not permitted by statutory regulation or exceeds the permitted use, you will need to obtain permission directly from the copyright holder. 